Document downloaded from:

http://hdl.handle.net/10251/120335

This paper must be cited as:

Salguero Barceló, FJ.; Cobacho Jordán, R.; Pardo Picazo, MA. (2019). Unreported leaks location using pressure and flow sensitivity in water distribution networks. Water Science \& Technology: Water Supply. 19(1):11-18. https://doi.org/10.2166/ws.2018.048

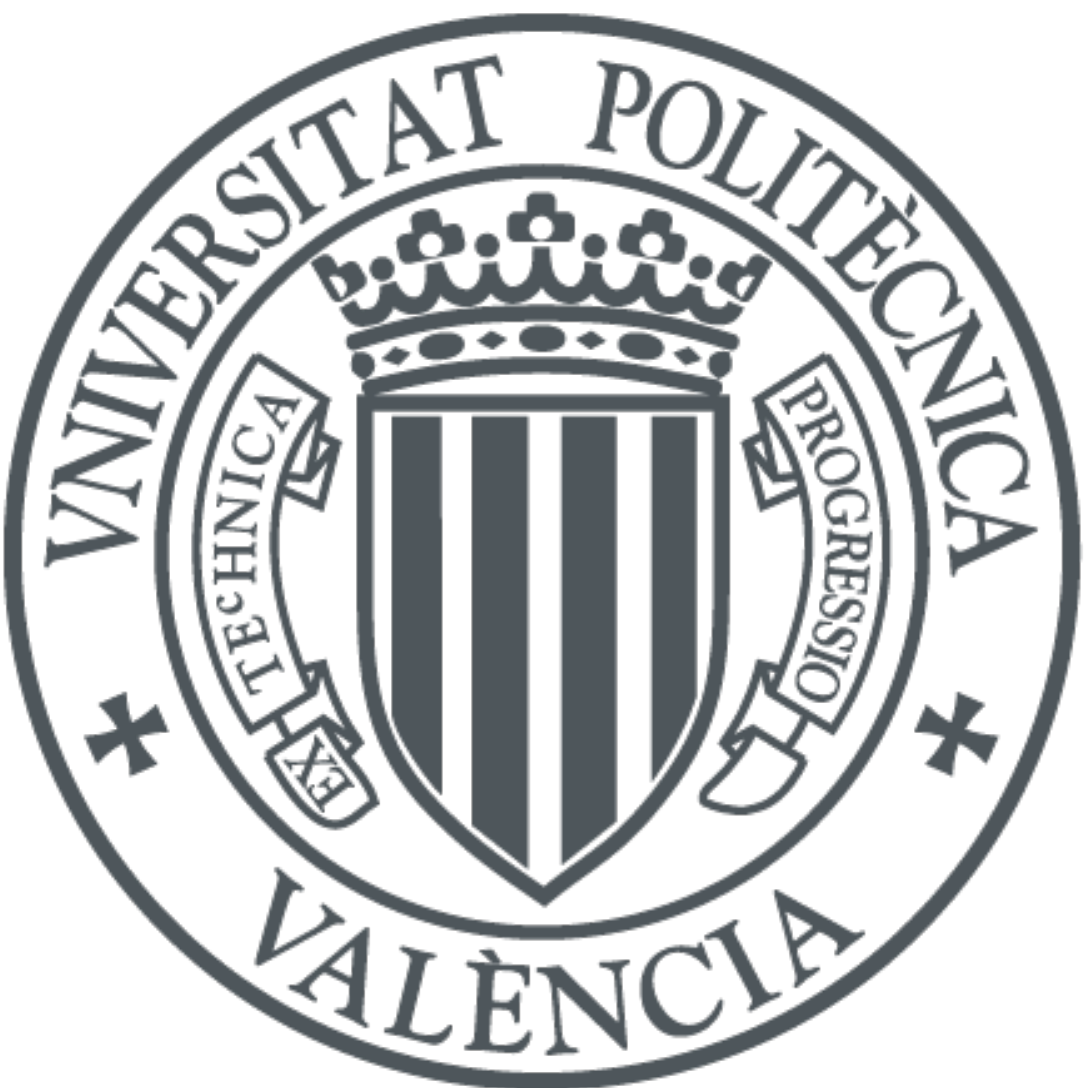

The final publication is available at

http://doi.org/10.2166/ws.2018.048

Copyright IWA Publishing

Additional Information 


\title{
Unreported Leaks Location using Pressure and Flow Sensitivity in Water Distribution Networks
}

\author{
F. J. Salguero*, R. Cobacho** and M.A. Pardo*** \\ * Water Utility Manager, Global Omnium-Aguas de Valencia. Gran Vía del Marqués del Turia, n 19 46005, \\ Valencia, Spain \\ (E-mail: fjsalguero@globalomnium.com) \\ ** Associate Professor, ITA, Dept. Hydraulic and Environmental Engineering, Universitat Politècnica de València, \\ C/Camino de Vera s/n. 46022, Valencia, Spain \\ (E-mail: rcobacho@ita.upv.es) \\ *** Assistant Professor, INGHA, Dept. de Ingeniería Civil, Universidad de Alicante, San Vicente del Raspeig, PO \\ Box 99, 03080, Alicante, Spain \\ (E-mail: mpardo@ua.es)
}

\begin{abstract}
Water distribution systems are made up of many interdependent elements that enable water supply to meet a demand that is variable in time and space. One of the main concerns for utility managers is quickly locating and repairing a leak after detection, during regular network water balance.

This paper presents a two-stage methodology for locating a leak that is based on the hydraulic model of the network, and, particularly, on the conservation equations that govern network behaviour.

In the first stage, the sensitivity of each element (nodes and pipes) is obtained for a given demand increase in any node. In the second stage, that sensitivity is combined with additional real data provided by the (possibly) existing pressure sensors and flow meters installed throughout the network. As a final result, the system of equations thus obtained produces the theoretical leak flow at each network node that matches the network conditions. A subsequent analysis of the leak flows obtained highlights the node or nodes in which the leak is occurring.

The presented methodoly is applied and assessed in a case study.
\end{abstract}

Keywords

Water leak detection; sensors; sensitivity analysis; hydraulic modelling

\section{INTRODUCTION}

Drinking water distribution systems in cities are large and complex infrastructures. Their operating points vary according to the demands at each moment and their management is complex - and even more so, if the appropriate renewal investments are not made. This complexity and gradual aging of the infrastructure does not help managers address one of the main problems in pressurized water distribution systems: the struggle against unreported leaks (IWA, 2000).

The traditional approach in the management of such leaks is essentially passive: the leaks are repaired when the water becomes visible, and so allowing leaks to run for weeks, months, or even years.

One of the most common policies to avoid wasting water is active leakage control (Charalambous et al, 2014, Berardi et al., 2016, Armon et al., 2011). This approach aims at early detection, location (Mounce et al., 2002), and repair of broken pipes - thereby reducing possible damage to third parties, minimising unplanned work, and reducing the volume of water lost.

Methods for the detection and monitoring of leaks are generally efficient, such as night minimum flows (Boulos \& Aboujaoude, 2011; Alkasseh et al., 2013), and sectorisation of networks (Gomes et al., 2012; Tzatchkov et al., 2014; Guistolisi \& Ridolfi, 2014). Once the existence of a leak is detected, it is located using acoustic techniques ( $\mathrm{Li}$, et al. 2015). For large networks this approach may require many resources and considerable time. 
New methodologies based on the sensorisation of distribution networks are gaining momentum for the rapid localisation of uncontrolled leaks. These methods are based on pressure measurement and sensitivity analysis of the distribution networks, taking advantage of the interdependence of all the operating parameters. These fundamentals were proposed by Pudar \& Liggett (1992), who studied the relationship between leaked volume, network pressure, and the leaking section. Most recent studies have focused the location of sensors to facilitate fault detection and maximise leak location performance (Blesa et al., 2016; Casillas et al., 2015; Gamboa-Medina \& Reis, 2017; Sarrate et al., 2014). The result depends on the number of sensors installed (Xie et al., 2017) and will be limited by the budget and strategy followed (Fuchs-Hanusch \& Steffelbauer, 2017). Based on the measurements of the pressure sensors, Perez et al. (2011) propose analysing the difference between said data and the equivalents provided by a simulation model, and in the event of a discrepancy, using the leak sensitivity matrix to determine the location. Under ideal conditions, these methodologies offer excellent results - but these results are less good if errors exist in the demands and measurements. To minimise this effect, subsequent studies (Casillas et al., 2014) introduce in their calculations an extended-period analysis of the measurements. Other authors propose similar approaches based on sensitivity analysis for locating leaks (Gamboa-medina \& Reis, 2017; Möderl et al., 2011; Steffelbauer et al., 2014); but all these approaches demand the posing of multiple scenarios and their corresponding simulations in a hydraulic model to explore the changes obtained. Considering the dynamic operation of distribution networks and the always unpredictable appearance of leaks, the time required for such analyses may limit their practical use.

The present work proposes a new methodology for locating leaks that is based on a simplified calculation of the sensitivity of the elements of the network. This methodology combines knowledge of the specific average behaviour of each element following an increase in demand at any point of the network, and the information provided by the pressure sensors. The aim is to produce a matrix formulation of the equations for the network behaviour in which the leak flows in each node are the unknowns, but which can continue to be resolved using the classical gradient procedure (Todini \& Pilati, 1987). Finally, the methodology is applied to a study network and the results are discussed.

Only two additional points need to be highlighted. The first is the versatility of the method: although the work is focused from the perspective of the location of the leak (real losses), the concepts used in the mathematical formulation mean it is equally applicable to the location of clandestine or unauthorised consumption. The second point is that this methodology is notable for its rapid calculation in the resolution of each scenario, which is one of its main advantages over similar studies, due to the vast number of combinations possible when locating leaks. 


\section{METHODOLOGY}

The methodology is presented in three sections. The first section (basic equations) is a reminder of the conservation equations that govern network behaviour. The contributions of the paper are developed in the second (sensitivity) and the third (location) sections.

\section{Basic equations}

Given a water network with $p$ pipes, $n$ nodes, and $m$ supply points, the method for modelling its hydraulic behaviour through conservation equations have already been soundly set (Todini \& Rossman, 2013; Todini \& Pilati, 1987). The first equation is the mass conservation equation applied to each network node:

$$
\sum_{k=1}^{n_{i}} Q_{i k_{0}}+q_{i}=0
$$

where $n_{i}$ is the total number of nodes connected to node $i, Q_{i k_{0}}$ is the circulating flowrate through the pipe that connects node $i$ to node $k$, and $q_{i}$ is the demand flowrate at node $i$.

The second equation is the energy conservation equation applied to each network pipe:

$$
H_{i_{0}}-H_{j_{0}}=h_{f_{i j_{0}}}=r_{i j} Q_{i j_{0}}\left|Q_{i j_{0}}\right|
$$

where $H_{i_{0}}$ and $H_{j_{0}}$ are the head values at nodes $i$ and $j$, respectively; $h_{f_{i j_{0}}}$ are the friction losses in the pipe that connects nodes $i$ and $j$; and $r_{i j}$ and $Q_{i j_{0}}$ are, respectively, hydraulic resistance and flowrate through the pipe between nodes $i$ and $j$.

Both sets of conservation equations, mass and energy, can be structured by means of matricial notation (Todini \& Pilati, 1987):

$$
\left[\begin{array}{ccc}
A_{11} & \vdots & A_{12} \\
\cdots & \cdots & \cdots \\
A_{21} & \vdots & 0
\end{array}\right] \cdot\left[\begin{array}{c}
Q \\
\cdots \\
H
\end{array}\right]=-\left[\begin{array}{c}
A_{10} \cdot H_{0} \\
q
\end{array}\right]
$$

where $A_{11}$ is a $(p \times p)$ diagonal matrix that represents the friction losses in each pipe; $A_{12}$ is a connectivity $(p \times n)$ matrix that relates nodes and pipes; $A_{21}$ is the transposed matrix of $A_{12} ; Q$ is the vector of the (unknown) circulating flows in pipes; $H$ is the vector of the (unkown) piezometric heads in the nodes; $A_{10}$ is the fixed head node incidence ( $p \times \mathrm{m}$ ) matrix; $H_{0}$ is the vector with the values of (known) fixed piezometric heads; and $q$ is the vector of (known) nodal demands.

\section{Network sensitivity (full equations development in Appendix A)}

To establish the effect of a demand increase throughout the network, this study tackles the sensitivity of the network and analyses the flow and pressure variation caused by small variations in water demand that are significant enough to affect the rest of elements. This study is structured in three steps. 
Step 1: Current situation: The first step is to solve the hydraulic performance of the network, obtaining the piezometric head in the nodes (vector $H$ ), and the flowrate circulating through the lines (vector $Q$ ). This is the base scenario for which the sensitivity is to be calculated.

Step 2: Definition of a consumption increase and consequences: if in node $i$, the current demand $\left(q_{i}\right)$ is increased $\left(\varphi_{q_{i}}\right)$, it will affect the new demand $\left(q_{i}+\varphi_{q_{i}}\right)$ and head $\left(H_{i_{0}}+\varphi_{H_{i_{i}}}\right)$ in node $i$, and the head $\left(H_{j_{0}}+\varphi_{H_{j_{i}}}\right)$ in any other node $j$, as well as the circulating flow in any pipe $\left(Q_{i k_{0}}+\varphi_{Q_{i k_{i}}}\right)$.

Therefore, the new formulation of the mass conservation equation in any node $i$ will be:

$$
\sum_{k=1}^{n_{i}}\left(Q_{i k_{0}}+\varphi_{Q_{i k_{i}}}\right)+q_{i}+\varphi_{q_{i}}=0
$$

where $\varphi_{Q_{i k_{i}}}$ is the flow variation of the pipe connecting nodes $i$ and $k$, produced by the demand variation in node $i$.

In parallel, the new energy conservation equation for any pipe (connecting nodes $i$ and $j$ ) will be:

$$
\left(H_{i_{0}}+\varphi_{H_{i_{i}}}\right)-\left(H_{j_{0}}+\varphi_{H_{j_{i}}}\right)-\vartheta_{i j} r_{i j} \cdot\left(Q_{i j_{0}}\left|Q_{i j_{0}}\right|+\frac{Q_{i j_{0}}{ }^{2} \cdot \varphi_{Q_{i j_{i}}}}{\left|Q_{i j_{0}}\right|}+\frac{Q_{i j_{0}} \cdot \varphi_{Q_{i j_{i}}}{ }^{2}}{\left|Q_{i j_{0}}\right|}+\varphi_{Q_{i j_{i}}}\left|Q_{i j_{0}}\right|\right)=0
$$

where $\vartheta$ is a term that adopts the value $\frac{Q_{i j_{0}} \cdot \varphi_{Q_{i j_{i}}}}{\left|Q_{i j_{0}}\right| \cdot\left|\varphi_{Q_{i j_{i}}}\right|}$ if $\left|\varphi_{Q_{i j_{i}}}\right|>\left|\mathrm{Q}_{\mathrm{ij}_{0}}\right|$ and the unit value otherwise.

Step 3: Calculation of network sensitivity: from the equations presented in the previous step, calculating the sensitivity of all the elements of the network is straightforward following a demand increase, in particular, in node $i$. Thus, it is suffice to solve the $p$ Equations 5 and the $n$ Equations 4, for the total of $p$ unknowns that correspond to the variation of the flow of each pipe $\varphi_{Q_{i j_{i}}}$ and the $n$ unknowns corresponding to the variation of the head of each node $\varphi_{H_{j_{i}}}$.

Since the network consists of $n$ nodes, the repetition $n$ times of this complete resolution of the network (one for each node) will give a complete view of the sensitivity of the network. Using this approach, a complete and quantified range of variation of the properties of each element is obtained. Although, this is perfectly feasible from the equations presented here, it may not be very operative in practice, since the calculation time for as many network resolutions as there are nodes, may be excessive. For this reason, the proposed method includes a simplification that means the system of network equations needs to be solved just once.

Instead of working separately with the specific variation in each element caused by the increase of flow in each node, the single average of all these variations is considered. That is, the general sensitivity of the head in each node $i$ is shown by:

$$
\varphi_{H_{i}}=\frac{\sum_{m=1}^{n} \varphi_{H_{i_{m}}}}{n}
$$


And the general sensitivity of the flowrate in each pipe $i k$, is shown by:

$$
\varphi_{Q_{i k}}=\frac{\sum_{m=1}^{n} \varphi_{Q_{i k_{m}}}}{n}
$$

By introducing these averages in the calculation of the sensitivity of the network elements, and also averaging all the $n$ equations for each node, then the total of $n \cdot(n+p)$ equations ( $n$ Equations 4 plus $p$ Equations 5, and multiplied by the $n$ nodes of the network) is reduced to $n$ node equations such as:

$$
\sum_{k=1}^{n_{i}}\left(Q_{i k_{0}}+\varphi_{Q_{i k}}\right)+q_{i}+\frac{\varphi_{q_{i}}}{n}=0
$$

and $p$ pipe equations such as:

$$
\left(H_{i_{0}}+\varphi_{H_{i}}\right)-\left(H_{j_{0}}+\varphi_{H_{j}}\right)-\vartheta_{\mathrm{ij}} \cdot \mathrm{r}_{\mathrm{ij}} \cdot\left(\mathrm{Q}_{i j_{0}} \cdot\left|\mathrm{Q}_{i j_{0}}\right|+\frac{\mathrm{Q}_{i j_{0}}{ }^{2} \cdot \varphi_{Q_{i j}}}{\left|\mathrm{Q}_{i j_{0}}\right|}+\frac{\mathrm{Q}_{i j_{0}} \cdot \varphi_{Q_{i j}}{ }^{2}}{\left|\mathrm{Q}_{i j_{0}}\right|}+\varphi_{Q_{i j}} \cdot\left|\mathrm{Q}_{i j_{0}}\right|\right)=0
$$

where $\varphi_{Q_{i j}} \mathrm{y} \varphi_{H_{i}}$ are, respectively, the average variation of the flow in pipe $i$, and the piezometric head in node $i$ produced by the consumption variation in any node. The new set of $n+p$ equations, with $n+p$ unknown factors can be expressed in a matrix format as follows:

$$
\left[\begin{array}{ccc}
A_{11 \varphi} & \vdots & A_{12} \\
\cdots & \cdots & \cdots \\
A_{21} & \vdots & 0
\end{array}\right]\left[\begin{array}{c}
\varphi_{Q} \\
\cdots \\
\varphi_{H}
\end{array}\right]=-\left[\begin{array}{ccc}
A_{11 \vartheta} & \vdots & A_{12} \\
\cdots & \cdots & \cdots \\
A_{21} & \vdots & 0
\end{array}\right]\left[\begin{array}{c}
Q \\
\cdots \\
H
\end{array}\right]-\left[\begin{array}{c}
A_{10} H_{0} \\
\cdots \\
q+\frac{\varphi_{q}}{n}
\end{array}\right]
$$

where $A_{12}, A_{21}, A_{10}, H_{0}$ and $q$ are the same terms as in Equation $3 ; H$ and $Q$ are the vectors explained in Step 1; $\varphi_{Q}$ is the vector of the (unknown) sensitivities (average variations) of flow in network pipes; $\varphi_{H}$ is the vector of the (unknown) sensitivities (average variations) of head in network nodes; $A_{11 \varphi}$ is a $\left(\begin{array}{lll}p & \mathrm{x} & p\end{array}\right)$ diagonal matrix with components $A_{11 \varphi}(r, r)=\vartheta_{\mathrm{ij}} \mathrm{r}_{\mathrm{ij}}\left(2\left|\mathrm{Q}_{i j_{0}}\right|+\frac{\mathrm{Q}_{i j_{0}}}{\left|\mathrm{Q}_{i j_{0}}\right|} \varphi_{Q_{i j}}\right)$, and $A_{11 \vartheta}$ is a $(p \mathrm{x} p)$ diagonal matrix with components $A_{11 \vartheta}(r, r)=\vartheta_{\mathrm{ij}} \mathrm{r}_{\mathrm{ij}}\left|\mathrm{Q}_{i j_{0}}\right|$.

The process for solving Equation 10 is the same for Equation 3 and, hence, the network sensitivity of an uncontrolled consumption of a given value at any node, can be calculated.

\section{Leak location (full equations development in Appendix B)}

In the case of a leak occurrence, whose magnitude and location (node) were known, the resulting pipe flows and node heads could be easily calculated by solving Equation 3. However, in water distribution networks, while estimating the magnitude of a newly detected leak though a quick water balance is not difficult, it is not so easy to determine its spatial location. In this leak scenario, new unknown factors must be introduced (Figure 1): circulating flows in pipes change $\left(Q_{i j_{L}}\right)$, node heads change $\left(H_{i_{L}}\right)$, and in addition to normal demand, a leak flow $\left(q_{i_{L}}\right)$ should be considered in each node. It is clear, that most of these added leak flows will be zero, and only those ones (ideally, just one) in the area close to the leak location will differ from zero, but there is usually no further information to clarify this question. Therefore, the new system would present $2 n+p$ unknown factors (which are the pressures and leak flowrates in the $n$ nodes and the flows through the $p$ pipes) and only $n+p$ equations. 


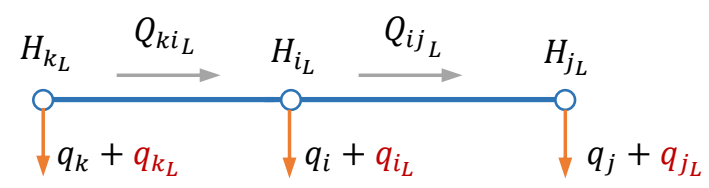

Figure 1. Hypothetical leaks in a distribution network

To limit the scope of the problem and find a finite and real solution, two sources of additional information can be introduced. The first takes advantage of the calculation of node sensitivity explained above. Since the real magnitude of a leak can be estimated through a quick water balance, the average head variation for each network node that corresponds to that magnitude of increase in demand, can also be calculated by Equation 10. Now the following hypothesis is proposed: in a leak situation the unknown piezometric head of any node can be approximated to the head under that node's normal working conditions plus its average calculated variation, $\left(H_{i_{L}}=H_{i_{0}}+\varphi_{H_{i}}\right)$. Therefore, $n$ terms corresponding to the node heads are now considered as known, and the new scenario can be solved.

The second source of additional information are the real measurements of the (likely) existing flow meters and pressure sensors installed in specific network pipes and nodes. Whatever the number of devices of each kind, the measurments they provide can be organised in a vector $H_{D}$ for the known node heads, and a vector $Q_{D}$ for the known flowrate pipes.

If these two new data sources are introduced into the equations that solve the hydraulic behaviour of the network, and the resulting set is simplified and adequately reordered, the following matrix formulation is produced:

$$
\left[\begin{array}{ccc}
A_{11} & \vdots & 0 \\
\cdots & \cdots & \cdots \\
A_{21} & \vdots & 1
\end{array}\right]\left[\begin{array}{c}
Q_{L} \\
\cdots \\
q_{L}
\end{array}\right]=-\left[\begin{array}{ccc}
A_{11} & \vdots & A_{12} \\
\cdots & \cdots & \cdots \\
A_{21} & \vdots & 0
\end{array}\right]\left[\begin{array}{c}
Q_{D} \\
\cdots \\
H_{D}
\end{array}\right]-\left[\begin{array}{c}
A_{10} H_{0} \\
\cdots \\
q
\end{array}\right]
$$

Where $A_{11}, A_{12}, A_{21}, A_{10}, H_{0}$ and $q$ are the same terms as in Equation $3, Q_{L}$ is the vector of the (unknown) pipe flows (in which values corresponding to flowmetered pipes are set to zero); $q_{L}$ is the vector of the (unknown) nodal leak flows; $Q_{D}$ is the vector of the (known) flowrates as measured by the meters in the pipes (and zero being the value for the rest of the pipes); $H_{D}$ is the vector of the (known) node heads (these values being directly measured by the pressure sensors installed in some nodes, or the approximation $H_{i_{0}}+\varphi_{H_{i}}$ for the rest of the nodes).

The two results obtained after solving Equation 11 are the circulating pipe flowrates and, most importantly, the leak flow in every node. A quick later analysis of the leak flow results will pinpoint the node (in the best case), or the area (at least) in which the leak is taking place. 


\section{CASE STUDY}

\section{Network description (full data in Appendix C)}

What follows is a case study of a synthetic network as shown in Figure 2. The network has a total length of $50 \mathrm{~km}$ with 58 pipelines that supply 38 consumption nodes whose elevation is zero. Some $6,500 \mathrm{~m}^{3}$ of water is delivered daily (40,000 inhabitants). Both reservoirs are elevated $50 \mathrm{~m}$. The pipe roughness is $0.1 \mathrm{~mm}$, and pipes lengths and diameters are shown in Table $\mathrm{C} 1$ (Appendix $\mathrm{C}$ ).

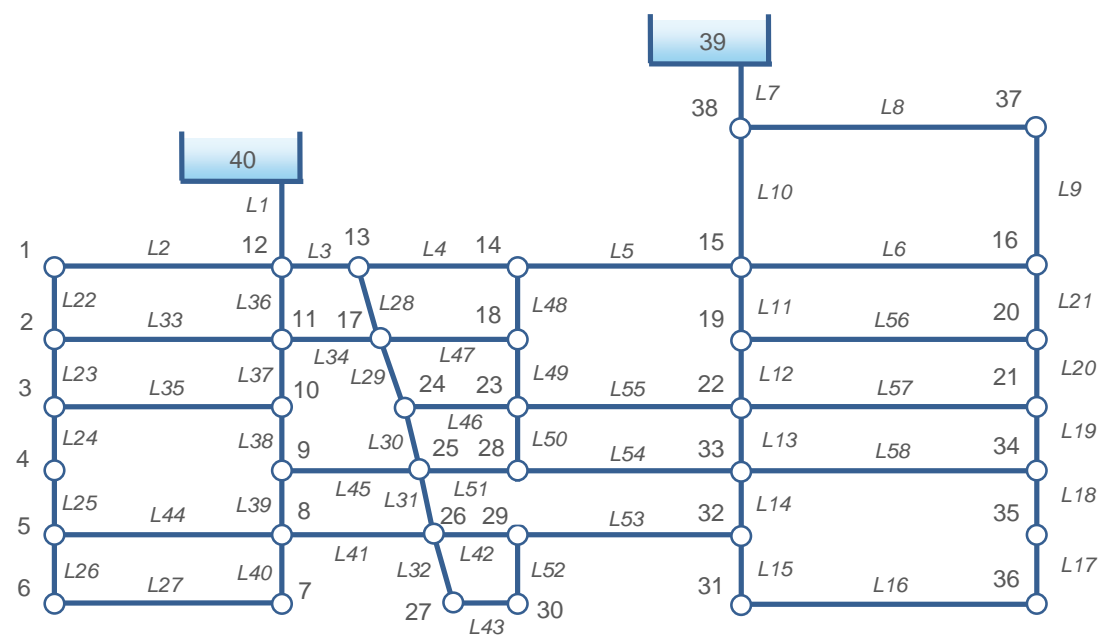

Figure 2. Layout of the distribution network

The base demand is $60 \mathrm{~L} /$ minute $\left(0.001 \mathrm{~m}^{3} / \mathrm{s}\right)$ for every node between 1 and 16 , and nodes 21,27 , and 30; while for the 19 remaining nodes, the base demand is $180 \mathrm{~L} /$ minute $\left(0.003 \mathrm{~m}^{3} / \mathrm{s}\right)$.

In its normal operating state, the average pressure is $37.7 \mathrm{mwc}$, with extreme values of 31.7 and $47.0 \mathrm{mwc}$ (Table C2). Average water velocity and unitary headloss in pipes are $0.41 \mathrm{~m} / \mathrm{s}$ and $2.50 \mathrm{mwc} / \mathrm{km}$, respectively (Table $\mathrm{C} 1$ ). The contribution of flow for each reservoir is approximately $50 \%$.

\section{Sensitivity analysis (full results in Appendix C)}

For an analysis of the sensitivity of the elements of the network, increments of 15,30 and $60 \mathrm{~L} /$ minute have been defined in each node. The reason is that the appearance of leaks from 15 or $30 \mathrm{~L} /$ minute on, in monitored sectors of a network may be detected using night flow analysis or automatic water balances. In addition, these figures are of the same order of magnitude as those considered by Fuchs-Hanusch \& Steffelbauer (2017).

After solving Equation 10 for all three scenarios, the detailed node results are shown in Table C2. As expected, the greater the increase in demand, the greater the decrease in pressure at the nodes (those that are furthest away from the inlet points being more affected). Thus, the average pressure decrease for network nodes in general is $-0.2 \%$ for $15 \mathrm{~L} /$ minute, and $-0.4 \%$ and $-0.9 \%$ for 30 and 60 $\mathrm{L} /$ minute, respectively. 
Sensitivity pipe results are shown in Table C3. Magnitudes of average flow changes for each demand increase $(15,30$ and $60 \mathrm{~L} /$ minute) are $0.52 \%, 1.05 \%$, and $2.13 \%$ (respectively). This gives a better idea of the real sensitivity and explains why the two pipes (27 and 44) with variations of more than $20 \%$ have two of the lowest network flowrates (about one hundred times less than the average flow per pipe).

The sensitivity analysis highlights those nodes with larger pressure variations (either in total or porcentage terms) - nodes 5, 6 and 25; as well as those whose changes are much less relevant, namely, nodes 12, 15 and 34. In parallel, the most sensitive pipes are 8, 36, and 37 (not taking into account those connecting each reservoir), whereas the least significant are 16, 43 and 46.

\section{Leak location (full results in Appendix D)}

Once the sensitivity analysis is completed, the problem of leak allocation is approached. For demonstrative purposes it is assumed that five pressure sensors and five flowmeters are available for installation in the network. The main criterion for the selection of the elements in which to install the sensors is that of greater sensitivity (as obtained in the previous calculation); while a secondary criterion is that of achieving a reasonable spatial distribution of the sensors. Accordingly, pressure sensors are installed in nodes 5, 18, 27, 30 and 37; and the flowmeters in pipes 1, 9, 20, 36 and 45 . That is, $13 \%$ of the nodes and $9 \%$ of the pipes are monitored.

The application and results of the leak location method are demonstrated as follows: it will be assumed, as each case is different, that a leak of $30 \mathrm{~L} /$ minute has occurred in each of the nodes of the network. That is, 38 different cases will be resolved. For each, in addition to knowing in which node the leak is located, the five real pressure values and five flowrate values provided, respectively, by the pressure sensors and flowmeters installed in the network, will be known (by direct simulation of the case). These ten items of data will be transferred to the model in which the method is tested, and whose information is completed for the rest of the nodes with the average head affected by the average sensitivity for an increase in demand of $30 \mathrm{~L} /$ minute. Finally, and through the resolution of Equation 11 the leak flow for each node is obtained (as well as the circulating pipe flows). The results are considered successful as the leak flow calculated is about 30 $\mathrm{L} /$ minute for the leaky node, or for neighbouring nodes, and is negligible for the other network nodes.

Table D2 (Appendix D) shows the obtained leak flow for each node (rows), measured in L/minute, for each of the simulations (columns). The table shows that the methodology has been successful in $63 \%$ ( 24 of the 38 simulations), since in 8 cases the leaking node was exactly identified (in green), and in 16 other cases the area was identified (node adjacent to the node with the leak - in yellow). From the data in Table D2 we can observe that the accurate location of the node, or the area where the uncontrolled leak is taking place, depends to some extent on the existence of a nearby flow or pressure sensor. It is also important to highlight the existence of nodes with a negative consumption (as in the case of node 36 for most simulations). It is apparent that some nodes may need a flow input to counterbalance the deviations introduced when estimating the known piezometric heads.

As expected, the leak location is less accurately shown if instead of choosing elements with a large variation in pressure and flow, those with a lower average variation are chosen. Thus, if nodes 1,12 , 15, 16 and 38, and pipes $6,16,43,46$ and 56 were selected, then less than $50 \%$ of the cases (16 of the 38) would be successful (Table D3). If sensitivity criteria is left aside and only spatial distribution criteria is considered, then the results show a greater variability. For example, if nodes 
2, 8, 18, 20 and 32; and pipes 11, 17, 25, 36 and 42 were monitored, the success rate would be exactly $50 \%$ (Table D4).

Logically, the more sensors installed in the network, the better the results. Thus, in Appendix D up to seven cases with different configurations of sensors are resolved, and a success rate of $87 \%$ is reached with 15 pressure sensors and 5 flowmeters. Generalised conclusions on the usefulness and versatility of the proposed method follow below.

\section{CONCLUSION}

Leakage control is a crucial part of the daily management of water distribution networks, and one of its key pillars is the rapid localisation of leaks. The range of instrumentation currently available for the monitoring of hydraulic variables in the network is very helpful in this task. Thus, pressure sensors and flow meters whose measurements can be transmitted in real time are frequently used, and this is of great value for the methodology proposed in this article. The number and location of these devices is limited by several factors, but mainly the cost of purchase, installation, and maintenance.

A methodology is proposed in this article that is doubly useful for the control of leaks. Firstly, based on the characteristics of the network and on the direct measurements provided by sensors, it reveals the location of a leak whose magnitude has been previously detected. Secondly, this same methodology can be used to determine the optimal location for the installation of sensors and control flow meters in a network - given that the effectiveness of any possible configuration can be simulated.

The potential provided by the proposed methodology for both objectives is based on its versatility and speed of calculation. Versatility because only the mathematical model of the network is needed and this is a very common support tool in supply management, and also because model equations are used directly - without need for (nor dependence on) specialised software. Thus, the speed of the resolution of the system of equations proposed here (using any spreadsheet and with a minimum of customised programming ability by the user) is the same, or even faster, than when using hydraulic simulation software.

The methodology itself is structured in two parts. In the first part, the sensitivity analysis focuses on the variations in the circulating flows and the piezometric heads in the nodes when a slight demand increase occurs. As a result, the average variation of these parameters is obtained and this enables a prioritisation of the hydraulic importance of the elements. The second part resolves mass and energy conservation equations - while considering as variables the unknown and uncontrolled water demands in each circulating flow and node, as well as considering an approximation of the piezometric head in the nodes as known variables. The measurements recorded by the pressure and flow sensors are considered as additional information. The final leak location may vary considerably depending on the number and location of the sensors, while the best locations for installing these sensors are on those elements whose variation is greater than average in the sensitivity analysis. This methodology is finally used in a case study network with a limited number of sensors to detect a water leak of $30 \mathrm{~L} /$ minute. 


\section{REFERENCES}

Armon, A., Gutner, S., Rosenberg, A. and Scolnicov, H. (2011). Algorithmic network monitoring for a modern water utility: a case study in Jerusalem. Journal of Water Science and Technology: Water Supply, 63 (2) 233-239. doi: 10.2166/wst.2011.041

Alkasseh, J., Adlan, M., Abustan, I., Aziz, H. and Hanif, A. (2013). Applying Minimum Night Flow to Estimate Water Loss Using Statistical Modeling: A Case Study in Kinta Valley, Malaysia. Water Resources Management (2013) 27:1439-1455. doi: 10.1007/s11269-012-0247-2

Berardi, L., Laucelli, D. B., Simone, A., Mazzolani, G., \& Giustolisi, O. (2016). Active Leakage Control with WDNetXL. Procedia Engineering, 154, 62-70. doi: 10.1016/j.proeng.2016.07.420

Blesa, J., Nejjari, F., \& Sarrate, R. (2016). Robust sensor placement for leak location: analysis and design. Journal of Hydroinformatics, 18(1), 136-148. doi: 10.2166/hydro.2015.021

Boulos, PF., and AbouJaoude, A.S. (2011). Managing leaks using flow step-testing, network modeling, and field measurement. J Am Water Works Assoc 103(2), 90-97

Casillas, M. V., Garza-Castañón, L. E., \& Cayuela, V. P. (2014). Model-based leak detection and location in water distribution networks considering an extended-horizon analysis of pressure sensitivities. Journal of Hydroinformatics, 16(3), 649-670. doi: 10.2166/hydro.2013.019

Casillas, M. V., Garza-Castañón, L. E., \& Puig, V. (2015). Sensor placement for leak location in water distribution networks using the leak signature space. IFAC-PapersOnLine, 48(21), 214219. doi: $10.1016 /$ j.ifacol.2015.09.530

Charalambous, B., Foufeas, D., \& Petroulias, N. (2014). Leak detection and water loss management. Water Utility Journal, 8, 25-30.

Fuchs-Hanusch, D., \& Steffelbauer, D. (2017). Real-world Comparison of Sensor Placement Algorithms for Leakage Localization. Procedia Engineering, 186, 499-505. doi: 10.1016/j.proeng.2017.03.262

Gamboa-Medina, M. M., \& Reis, L. F. R. (2017). Sampling Design for Leak Detection in Water Distribution Networks. Procedia Engineering, 186, 460-469. doi: 10.1016/j.proeng.2017.03.255

Gomes, R., Marques, A.S. and Sousa, J. (2012). Decision support system to divide a large network into suitable District Metered Areas. Journal of Water Science and Technology:Water Supply, 65 (9) 1667-1675. doi: 10.2166/wst.2012.061

Guistolisi, O. and Ridolfi, L. (2014). New Modularity-based approach to segmentation of water distribution networks. Journal of Hydraulic engineering, 140(10):04014049. doi: 10.1061/(ASCE)HY.1943-7900.0000916

IWA, International Water Association (2000). Losses from Water Supply Systems: Standard Terminology and Recommended Performance Measures. IWA, International Water AssociationTask Force on Water Losses, London, 2000. 
Li, R., Huang, H., Xin, K. and Tao (2015). A review of methods for burst/leakage detection and location in water distribution systems. Journal of Water Science and Technology: Water Supply, 15 (3) 429-441. doi: 10.2166/ws.2014.131

Möderl, M., Hellbach, C., Sitzenfrei, R., Mair, M., Lukas, A., Mayr, E., \& Rauch, W. (2011). GIS based applications of sensitivity analysis for water distribution models. In World Environmental and Water Resources Congress 2011: Bearing Knowledge for Sustainability (pp. 129-136). doi: $10.1061 / 41173(414) 14$

Mounce, S., Day, A.J., Wood, A.S., Khan, A., Widdop, P. D. and Machell, J. (2002). A neural network approach to burst detection. Journal of Water Science and Technology:Water Supply, 45( 4-5): 237-246

Pérez, R., Puig, V., Pascual, J., Quevedo, J., Landeros, E., and Peralta, A. (2011). Methodology for leakage isolation using pressure sensitivity analysis in water distribution networks. Control Engineering Practice, 19(10), 1157-1167. doi: 10.1016/j.conengprac.2011.06.004

Pudar, R. S., and Liggett, J. A. (1992). Leaks in pipe networks. Journal of Hydraulic Engineering, 118(7), 1031-1046.

Sarrate, R., Blesa, J., Nejjari, F., \& Quevedo, J. (2014). Sensor placement for leak detection and location in water distribution networks. Water Science and Technology: Water Supply, 14(5), 795803. doi: $10.2166 /$ ws.2014.037

Steffelbauer, D., Neumayer, M., Günther, M., \& Fuchs-Hanusch, D. (2014). Sensor placement and leakage localization considering demand uncertainties. Procedia Engineering, 89, 1160-1167. doi: 10.1016/j.proeng.2014.11.242

Todini, E., and Pilati, S. (1987, September). A gradient method for the analysis of pipe networks. In International Conference on Computer Applications for Water Supply and Distribution, Leicester Polytechnic, UK.

Todini, E., and Rossman, L. A. (2013). Unified framework for deriving simultaneous equation algorithms for water distribution networks. Journal of Hydraulic Engineering, 139(5), 511-526. doi: 10.1061/(ASCE)HY.1943-7900.0000703

Tzatchkov, V., Alcocer, V., Bourguett, V. Arreguín, F. \& López, JA. (2014). Avances en la hidráulica de redes de distribución de agua potable. México. Instituto Mexicano de Tecnología del Agua. ISBN: 978-607-9368-11-1.

Xie, X., Zhou, Q., Hou, D., \& Zhang, H. (2017). Compressed sensing based optimal sensor placement for leak localization in water distribution networks. Journal of Hydroinformatics, jh2017145. doi: 10.2166/hydro.2017.145 


\section{Appendix A. Development of equations for network sensitivy}

Development of equations to calculate the network sensitivity.

The mass conservation equation for each node $i$, in normal conditions with no leaks is:

$$
\sum_{k=1}^{n_{i}} Q_{i k_{0}}+q_{i}=0
$$

where $n_{i}$ is the total number of nodes connected to node $i, Q_{i k_{0}}$ is the circulating flowrate through the pipe that connects node $i$ to node $k$, and $q_{i}$ is the demand flowrate at node $i$.

If the demand at node $i$ is increased by a given amount $\left(\varphi_{q_{i}}\right)$ because of a leak occurrence:

- $\quad$ The new demand at node $i$ will be: $q_{i}+\varphi_{q_{i}}$

- A variation in the circulating flowrate through the pipe that connects node $i$ to node $k$ will appear. That variation will be $\varphi_{Q_{i k_{i}}}$, and the new pipe flowrate will be: $Q_{i k_{0}}+\varphi_{Q_{i k_{i}}}$

- The new mass conservation equation for node $i$ (due to a demand increase at node $i$ ) will be:

$$
\sum_{k=1}^{n_{i}}\left(Q_{i k_{0}}+\varphi_{Q_{i k_{i}}}\right)+q_{i}+\varphi_{q_{i}}=0
$$

- The new mass conservation equation for any other node $j$ (due to a demand increase at node $i$ ) will be:

$$
\sum_{k=1}^{n_{j}}\left(Q_{j k_{0}}+\varphi_{Q_{j k_{i}}}\right)+q_{j}=0
$$


If the mass conservation equation is considered for each node $i$, in each case a demand increase occurs in each one of the network nodes, the complete set of $n$ equations for node $i$ will be:

\begin{tabular}{|c|c|c|}
\hline $\begin{array}{l}\text { Node } \\
\text { i }\end{array}$ & $\begin{array}{c}\text { Demand } \\
\text { increase } \\
\text { in node }\end{array}$ & Mass conservation equation (for node $i$ ) \\
\hline \multirow{8}{*}{$i$} & 1 & $\left(Q_{i 1_{0}}+\varphi_{Q_{i 1_{1}}}\right)+\cdots+\left(Q_{i k_{0}}+\varphi_{Q_{i k_{1}}}\right)+\cdots+\left(Q_{i n_{i_{0}}}+\varphi_{Q_{i n_{i_{1}}}}\right)+\left(q_{i}\right)=0$ \\
\hline & 2 & $\left(Q_{i 1_{0}}+\varphi_{Q_{i 1_{2}}}\right)+\cdots+\left(Q_{i k_{0}}+\varphi_{Q_{i k_{2}}}\right)+\cdots+\left(Q_{i n_{i_{0}}}+\varphi_{Q_{i n_{i_{2}}}}\right)+\left(q_{i}\right)=0$ \\
\hline & $\ldots$ & $\ldots$ \\
\hline & $m$ & $\left(Q_{i 1_{0}}+\varphi_{Q_{i 1_{m}}}\right)+\cdots+\left(Q_{i k_{0}}+\varphi_{Q_{i k_{m}}}\right)+\cdots+\left(Q_{i n_{i_{0}}}+\varphi_{Q_{i n_{i_{m}}}}\right)+\left(q_{i}\right)=0$ \\
\hline & $\ldots$ & $\ldots$ \\
\hline & $i$ & $\left(Q_{i 1_{0}}+\varphi_{Q_{i 1_{i}}}\right)+\cdots+\left(Q_{i k_{0}}+\varphi_{Q_{i k_{i}}}\right)+\cdots+\left(Q_{i n_{i_{0}}}+\varphi_{Q_{i n_{i}}}\right)+\left(q_{i}+\varphi_{q_{i}}\right)=0$ \\
\hline & $\ldots$ & $\cdots$ \\
\hline & $n$ & $\left(Q_{i 1_{0}}+\varphi_{Q_{i 1_{n}}}\right)+\cdots+\left(Q_{i k_{0}}+\varphi_{Q_{i k_{n}}}\right)+\cdots+\left(Q_{i n_{i_{0}}}+\varphi_{Q_{i n_{i n}}}\right)+\left(q_{i}\right)=0$ \\
\hline
\end{tabular}

The result of adding the $n$ equations for node $i$ is:

$$
\begin{gathered}
\sum_{k=1}^{n_{i}}\left(n Q_{i k_{0}}\right)+\sum_{k=1}^{n_{i}}\left(\sum_{m=1}^{n} \varphi_{Q_{i k_{m}}}\right)+n q_{i}+\varphi_{q_{i}}=0 \\
\sum_{k=1}^{n_{i}}\left(n Q_{i k_{0}}+\sum_{m=1}^{n} \varphi_{Q_{i k_{m}}}\right)+n q_{i}+\varphi_{q_{i}}=0
\end{gathered}
$$

The average variation for each pipe flowrate, after considering the influence of a leak at each of the $n$ nodes of the network is:

$$
\varphi_{Q_{i k}}=\frac{\sum_{m=1}^{n} \varphi_{Q_{i k_{m}}}}{n}
$$

If Equation A5 is replaced in Equation A4, and the resulting equation is devided by $n$, the final mass conservation equation for node $i$ is:

$$
\sum_{k=1}^{n_{i}}\left(Q_{i k_{0}}+\varphi_{Q_{i k}}\right)+q_{i}+\frac{\varphi_{q_{i}}}{n}=0
$$

The first part of the sensitivity analysis is performed by considering the same demand increase $\left(\varphi_{q}\right.$ taken as a constant value) for each node, and posing the whole set of the mass conservation equations for all the network nodes: 


\begin{tabular}{|c|c|}
\hline Node Id & \multicolumn{1}{|c}{ Mass conservation equation } \\
\hline 1 & $\sum_{k=1}^{n_{1}}\left(Q_{1 k_{0}}+\varphi_{Q_{1 k}}\right)+q_{1}+\frac{\varphi_{q}}{n}=0$ \\
\hline 2 & $\sum_{k=1}^{n_{2}}\left(Q_{2 k_{0}}+\varphi_{Q_{2 k}}\right)+q_{2}+\frac{\varphi_{q}}{n}=0$ \\
\hline$\ldots$ & $\ldots$ \\
\hline$m$ & $\sum_{k=1}^{n_{m}}\left(Q_{m k_{0}}+\varphi_{Q_{m k}}\right)+q_{m}+\frac{\varphi_{q}}{n}=0$ \\
\hline$\ldots$ & $\sum_{k=1}^{n_{n}}\left(Q_{n k_{0}}+\varphi_{Q_{n k}}\right)+q_{n}+\frac{\varphi_{q}}{n}=0$ \\
\hline
\end{tabular}

System A7 is compounded by $n$ equations, with $p$ unknowns - the average flowrate sensitivity for each one of the $p$ pipes. According to the matrix formulation used by Todini \& Rossman (2013) this system can be expressed as:

$$
\left[A_{21}\right]\left[Q+\varphi_{Q}\right]+\left[q+\frac{\varphi_{q}}{n}\right]=0
$$

where:

- $A_{21}$ is a $(n \times p)$ matrix that relates $n$ nodes to $p$ pipes, so that each element $A_{21}(q, r)$ takes the value:

$$
\begin{array}{rrl}
\circ & -1 & \text { if pipe } r \text { leaves node } q \\
\circ & 0 & \text { if pipe } r \text { is not connected to node } q \\
\circ & +1 & \text { if pipe } r \text { enters node } q
\end{array}
$$

- $Q$ is the vector of the pipe flowrates $Q_{i j_{0}}$

- $\varphi_{Q}$ is the vector of the pipe flowrate average sensitivities $\varphi_{Q_{i j}}$

- $q$ is the vector of the node demands $q_{i}$

- $\frac{\varphi_{q}}{n}$ is the vector of the node demand variations. As explained above, since the sensitivity is calculated for the same demand variation in each node, this vector has a unique value for all the nodes.

Finally, Equation A8 can be operated to the final expression:

$$
\left[A_{21} \varphi_{Q}\right]=-\left[A_{21} Q\right]-\left[q_{i}+\frac{\varphi_{q}}{n}\right]
$$


The energy conservation equation for each pipe, which connects node $i$ to node $j$, in normal conditions with no leaks is:

$$
H_{i_{0}}-H_{j_{0}}=h_{f_{i j_{0}}}=r_{i j} Q_{i j_{0}}\left|Q_{i j_{0}}\right|
$$

where $H_{i_{0}}$ and $H_{j_{0}}$ are the piezometric heads at nodes $i$ and $j$, respectively; $h_{f_{i j_{0}}}$ is the pipe friction headloss; and $r_{i j}$ and $Q_{i j_{0}}$ are the pipe hydraulic resistance and pipe flowrate, respectively.

If the demand at node $i$ is increased by a given amount $\left(\varphi_{q_{i}}\right)$, because of a leak occurrence:

- A variation in the circulating flowrate through the pipe that connects node $i$ to node $j$ will appear - and in any other pipe of the network as well. That variation will be $\varphi_{Q_{i j_{i}}}$, and the new pipe flowrate will be: $Q_{i j_{0}}+\varphi_{Q_{i j_{i}}}$.

- A variation in the piezometric head of nodes $i$ and $j$ will appear - and also in any other node of the network. Those variations will be $\varphi_{H_{i_{i}}}$ and $\varphi_{H_{j_{i}}}$, respectively, and the new piezometric heads will be: $H_{i_{0}}+\varphi_{H_{i_{i}}}$ and $H_{j_{0}}+\varphi_{H_{j_{i}}}$.

- The new energy conservation equation for pipe $i j$ (due to a demand increase at node $i$ ) will be:

$$
\left(H_{i_{0}}+\varphi_{H_{i_{i}}}\right)-\left(H_{j_{0}}+\varphi_{H_{j_{i}}}\right)=r_{i j}\left(Q_{i j_{0}}+\varphi_{Q_{i j_{i}}}\right)\left|\left(Q_{i j_{0}}+\varphi_{Q_{i j_{i}}}\right)\right|
$$

- The new energy conservation equation for pipe $m n$ (due to a demand increase at node $i$ ) will be:

$$
\left(H_{m_{0}}+\varphi_{H_{m_{i}}}\right)-\left(H_{n_{0}}+\varphi_{H_{n_{i}}}\right)=r_{m n}\left(Q_{m n_{0}}+\varphi_{Q_{m n_{i}}}\right)\left|\left(Q_{m n_{0}}+\varphi_{Q_{m n_{i}}}\right)\right|
$$

\begin{tabular}{|c|c|c|}
\hline Pipe & $\begin{array}{c}\text { Demand } \\
\text { increase } \\
\text { in node }\end{array}$ & Energy conservation equation (for pipe $i j$ ) \\
\hline \multirow{8}{*}{$i j$} & 1 & $\left(H_{i_{0}}+\varphi_{H_{i_{1}}}\right)-\left(H_{j_{0}}+\varphi_{H_{j_{1}}}\right)=r_{i j}\left(Q_{i j_{0}}+\varphi_{Q_{i j_{1}}}\right)\left|\left(Q_{i j_{0}}+\varphi_{Q_{i j_{1}}}\right)\right|$ \\
\hline & 2 & $\left(H_{i_{0}}+\varphi_{H_{i_{2}}}\right)-\left(H_{j_{0}}+\varphi_{H_{j_{2}}}\right)=r_{i j}\left(Q_{i j_{0}}+\varphi_{Q_{i j_{2}}}\right)\left|\left(Q_{i j_{0}}+\varphi_{Q_{i j_{2}}}\right)\right|$ \\
\hline & $\ldots$ & $\ldots$ \\
\hline & $i$ & $\left(H_{i_{0}}+\varphi_{H_{i_{i}}}\right)-\left(H_{j_{0}}+\varphi_{H_{j_{i}}}\right)=r_{i j}\left(Q_{i j_{0}}+\varphi_{Q_{i j_{i}}}\right)\left|\left(Q_{i j_{0}}+\varphi_{Q_{i j_{i}}}\right)\right|$ \\
\hline & $\ldots$ & $\ldots$ \\
\hline & $j$ & $\left(H_{i_{0}}+\varphi_{H_{i_{j}}}\right)-\left(H_{j_{0}}+\varphi_{H_{j_{j}}}\right)=r_{i j}\left(Q_{i j_{0}}+\varphi_{Q_{i j_{j}}}\right)\left|\left(Q_{i j_{0}}+\varphi_{Q_{i j_{j}}}\right)\right|$ \\
\hline & $\ldots$ & $\ldots$ \\
\hline & $n$ & $\left(H_{i_{0}}+\varphi_{H_{i_{n}}}\right)-\left(H_{j_{0}}+\varphi_{H_{j_{n}}}\right)=r_{i j}\left(Q_{i j_{0}}+\varphi_{Q_{i j_{n}}}\right)\left|\left(Q_{i j_{0}}+\varphi_{Q_{i j_{n}}}\right)\right|$ \\
\hline
\end{tabular}

If the energy conservation equation is considered for any pipe $i j$, in each case a demand increase occurs in each one of the network nodes, the complete set of $n$ equations for pipe $i j$ will be: 
The equations of System A11 cannot be easily added, so the following operation is considered:

$$
(Q+\varphi)|(Q+\varphi)|=\vartheta\left(Q|Q|+\frac{Q^{2} \varphi}{|Q|}+\frac{Q \varphi^{2}}{|Q|}+\varphi|Q|\right)
$$

where:

- $\vartheta=\frac{Q \varphi}{|Q||\varphi|}$, if $|\varphi|>|Q|$

- $\vartheta=1$, if $|\varphi| \leq|Q|$

and the new set of $n$ energy conservation equations for pipe $i j$ is:

\begin{tabular}{|c|c|c|}
\hline Pipe & $\begin{array}{l}\text { Demand } \\
\text { increase } \\
\text { in node }\end{array}$ & Energy conservation equation (for pipe $i j$ ) \\
\hline \multirow{8}{*}{$i j$} & 1 & $\left(H_{i_{0}}+\varphi_{H_{i_{1}}}\right)-\left(H_{j_{0}}+\varphi_{H_{j_{1}}}\right)-\vartheta_{\mathrm{ij}} \mathrm{r}_{\mathrm{ij}} \cdot\left(\mathrm{Q}_{i j_{0}}\left|\mathrm{Q}_{i j_{0}}\right|+\frac{\mathrm{Q}_{i j_{0}}{ }^{2} \cdot \varphi_{Q_{i j_{1}}}}{\left|\mathrm{Q}_{i j_{0}}\right|}+\frac{\mathrm{Q}_{i j_{0}} \cdot \varphi_{Q_{i j_{1}}}{ }^{2}}{\left|\mathrm{Q}_{i j_{0}}\right|}+\varphi_{Q_{i j_{1}}}\left|\mathrm{Q}_{i j_{0}}\right|\right)=0$ \\
\hline & 2 & $\left(H_{i_{0}}+\varphi_{H_{i_{2}}}\right)-\left(H_{j_{0}}+\varphi_{H_{j_{2}}}\right)-\vartheta_{\mathrm{ij}} \mathrm{r}_{\mathrm{ij}} \cdot\left(Q_{i j_{0}}\left|Q_{i j_{0}}\right|+\frac{\mathrm{Q}_{i j_{0}}{ }^{2} \cdot \varphi_{Q_{i j_{2}}}}{\left|\mathrm{Q}_{i j_{0}}\right|}+\frac{\mathrm{Q}_{i j_{0}} \cdot \varphi_{Q_{i j_{2}}}{ }^{2}}{\left|\mathrm{Q}_{i j_{0}}\right|}+\varphi_{Q_{i j_{2}}}\left|Q_{i j_{0}}\right|\right)=0$ \\
\hline & $\ldots$ & $\ldots$ \\
\hline & $i$ & $\left(H_{i_{0}}+\varphi_{H_{i_{i}}}\right)-\left(H_{j_{0}}+\varphi_{H_{j_{i}}}\right)-\vartheta_{\mathrm{ij}} \mathrm{r}_{\mathrm{ij}} \cdot\left(\mathrm{Q}_{i j_{0}}\left|\mathrm{Q}_{i j_{0}}\right|+\frac{\mathrm{Q}_{i j_{0}}{ }^{2} \cdot \varphi_{Q_{i j_{i}}}}{\left|\mathrm{Q}_{i j_{0}}\right|}+\frac{\mathrm{Q}_{i j_{0}} \cdot \varphi_{Q_{i j_{i}}}{ }^{2}}{\left|\mathrm{Q}_{i j_{0}}\right|}+\varphi_{Q_{i j_{i}}}\left|\mathrm{Q}_{i j_{0}}\right|\right)=0$ \\
\hline & $\ldots$ & $\ldots$ \\
\hline & $j$ & $\left(H_{i_{0}}+\varphi_{H_{i_{j}}}\right)-\left(H_{j_{0}}+\varphi_{H_{j_{j}}}\right)-\vartheta_{\mathrm{ij}} \mathrm{r}_{\mathrm{ij}} \cdot\left(\mathrm{Q}_{i j_{0}}\left|\mathrm{Q}_{i j_{0}}\right|+\frac{\mathrm{Q}_{i j_{0}}{ }^{2} \cdot \varphi_{Q_{i j_{j}}}}{\left|\mathrm{Q}_{i j_{0}}\right|}+\frac{Q_{i j_{0}} \cdot \varphi_{Q_{i j_{j}}}{ }^{2}}{\left|\mathrm{Q}_{i j_{0}}\right|}+\varphi_{Q_{i j_{j}}}\left|\mathrm{Q}_{i j_{0}}\right|\right)=0$ \\
\hline & $\ldots$ & $\cdots$ \\
\hline & $n$ & $\left(H_{i_{0}}+\varphi_{H_{i_{n}}}\right)-\left(H_{j_{0}}+\varphi_{H_{j_{n}}}\right)-\vartheta_{\mathrm{ij}} \mathrm{r}_{\mathrm{ij}} \cdot\left(\mathrm{Q}_{i j_{0}}\left|\mathrm{Q}_{i j_{0}}\right|+\frac{\mathrm{Q}_{i j_{0}}{ }^{2} \cdot \varphi_{Q_{i j_{n}}}}{\left|\mathrm{Q}_{i j_{0}}\right|}+\frac{\mathrm{Q}_{i j_{0}} \cdot \varphi_{Q_{i j_{n}}}{ }^{2}}{\left|\mathrm{Q}_{i j_{0}}\right|}+\varphi_{Q_{i j_{n}}}\left|\mathrm{Q}_{i j_{0}}\right|\right)=0$ \\
\hline
\end{tabular}

Before adding the $n$ Equations A13 for pipe $i j$, it must be noticed that $\frac{\sum_{m=1}^{n} \varphi_{Q_{i j m}}{ }^{2}}{n}$ is the mean square of the $\varphi_{Q_{i j m}}$ values. However, being $\varphi_{Q_{i j}}$ the variable to be finally solved, the simplification $\frac{\sum_{m=1}^{n} \varphi_{Q_{i j m}}{ }^{2}}{n} \approx \varphi_{Q_{i j}}{ }^{2}$ is assumed. This is based on the fact that, compared to the other terms within the parenthesis, $\frac{\mathrm{Q}_{i j_{0}} \cdot \varphi_{Q_{i j_{n}}}{ }^{2}}{\left|\mathrm{Q}_{i j_{0}}\right|}$ is the least relevant because of the magnitude of either $\varphi_{Q_{i j}}{ }^{2}$ (compared to $\varphi_{Q_{i j}}$ ), or $\frac{\mathrm{Q}_{i j_{0}}}{\left|\mathrm{Q}_{i j_{0}}\right|}$ (compared to $\left|\mathrm{Q}_{i j_{0}}\right|$ ). The final result of the addition of the $n$ equations for pipe $i j$ is:

$n H_{i_{0}}+\sum_{m=1}^{n} \varphi_{H_{i_{m}}}-n H_{j_{0}}-\sum_{m=1}^{n} \varphi_{H_{j_{m}}}-\vartheta_{\mathrm{ij}} \mathrm{r}_{\mathrm{ij}} \cdot\left(\mathrm{n} \mathrm{Q}_{i j_{0}}\left|\mathrm{Q}_{i j_{0}}\right|+\frac{\mathrm{Q}_{i j_{0}}{ }^{2}}{\left|\mathrm{Q}_{i j_{0}}\right|} \sum_{m=1}^{n} \varphi_{Q_{i j_{m}}}+\frac{\mathrm{Q}_{i j_{0}}}{\left|\mathrm{Q}_{i j_{0}}\right|} \sum_{m=1}^{n} \varphi_{Q_{i j_{m}}}{ }^{2}+\left|\mathrm{Q}_{i j_{0}}\right| \sum_{m=1}^{n} \varphi_{Q_{i j_{m}}}\right)=0$ 
Again, total average variations for each network element can be considered:

- $\quad$ For pipe $i k: \varphi_{Q_{i k}}=\frac{\sum_{m=1}^{n} \varphi_{Q_{i k_{m}}}}{n}$

- For node $i: \varphi_{H_{i}}=\frac{\sum_{m=1}^{n} \varphi_{H_{i_{m}}}}{n}$

As these two averages are considered in Equation A14, and the resulting equation is divided by $n$, the final energy conservation equation for each pipe $i j$ will be:

$$
\begin{aligned}
& \left(H_{i_{0}}+\varphi_{H_{i}}\right)-\left(H_{j_{0}}+\varphi_{H_{j}}\right)-\vartheta_{\mathrm{ij}} \mathrm{r}_{\mathrm{ij}} \cdot\left(Q_{i j_{0}}\left|Q_{i j_{0}}\right|+\frac{{\mathrm{Q}_{i j_{0}}}^{2}}{\left|Q_{i j_{0}}\right|} \varphi_{Q_{i j}}+\frac{Q_{i j_{0}}}{\left|Q_{i j_{0}}\right|} \varphi_{Q_{i j}}{ }^{2}+\left|Q_{i j_{0}}\right| \varphi_{Q_{i j}}\right)=0 \\
& H_{i_{0}}+\varphi_{H_{i}}-H_{j_{0}}-\varphi_{H_{j}}-\vartheta_{\mathrm{ij}} \mathrm{r}_{\mathrm{ij}} \cdot\left(\mathrm{Q}_{i j_{0}}\left|\mathrm{Q}_{i j_{0}}\right|+\frac{\mathrm{Q}_{i j_{0}}{ }^{2}}{\left|\mathrm{Q}_{i j_{0}}\right|} \varphi_{Q_{i j}}+\frac{\mathrm{Q}_{i j_{0}}}{\left|Q_{i j_{0}}\right|} \varphi_{Q_{i j}}{ }^{2}+\left|Q_{i j_{0}}\right| \varphi_{Q_{i j}}\right)=0 \\
& \vartheta_{\mathrm{ij}} \mathrm{r}_{\mathrm{ij}} \cdot\left(2\left|\mathrm{Q}_{i j_{0}}\right|+\frac{\mathrm{Q}_{i j_{0}}}{\left|\mathrm{Q}_{i j_{0}}\right|} \varphi_{Q_{i j}}\right) \varphi_{Q_{i j}}-\varphi_{H_{i}}+\varphi_{H_{j}}+\vartheta_{\mathrm{ij}} \mathrm{r}_{\mathrm{ij}} \mathrm{Q}_{i j_{0}}\left|\mathrm{Q}_{i j_{0}}\right|-H_{i_{0}}+H_{j_{0}}=0
\end{aligned}
$$

The second part of the sensitivity analysis is performed by posing the whole set of energy conservation equations for all the network pipes:

\begin{tabular}{|c|c|c|}
\hline \multicolumn{2}{|c|}{ Pipe } & Energy conservation equation (for pipe $r \equiv i j$ ) \\
\hline Id & $\begin{array}{c}\text { Nodes } \\
\text { connected }\end{array}$ & $\ldots$ \\
\hline 1 & $\ldots$ & $\ldots$ \\
\hline 2 & $\ldots$ & $\ldots$ \\
\hline$\ldots$ & $\ldots$ & $\ldots$ \\
\hline$r$ & $i j$ & $\vartheta_{\mathrm{ij}} \mathrm{r}_{\mathrm{ij}} \cdot\left(2\left|\mathrm{Q}_{i j_{0}}\right|+\frac{\mathrm{Q}_{i j_{0}}}{\left|\mathrm{Q}_{i j_{0}}\right|} \varphi_{Q_{i j}}\right) \varphi_{Q_{i j}}-\varphi_{H_{i}}+\varphi_{H_{j}}+\vartheta_{\mathrm{ij}} \mathrm{r}_{\mathrm{ij}} \mathrm{Q}_{i j_{0}}\left|\mathrm{Q}_{i j_{0}}\right|-H_{i_{0}}+H_{j_{0}}=0$ \\
\hline$\ldots$ & $\ldots$ & $\ldots$ \\
\hline$p$ & $\ldots$ & $\ldots$ \\
\hline
\end{tabular}

System A18 is compounded by $p$ equations, with $(n+p)$ unknowns - the head average sensitivity for each of the $n$ nodes $\left(\varphi_{H_{i}}\right)$, and the flowrate average sensitivity for each of the $p$ pipes $\left(\varphi_{Q_{i j}}\right)$. According to the matrix formulation used by Todini \& Rossman (2013), this system can be expressed as:

$$
\left[\begin{array}{lll}
A_{11 \varphi} & \vdots & A_{12}
\end{array}\right]\left[\begin{array}{c}
\varphi_{Q} \\
\cdots \\
\varphi_{H}
\end{array}\right]+\left[\begin{array}{lll}
A_{11 \vartheta} & \vdots & A_{12}
\end{array}\right]\left[\begin{array}{c}
Q \\
\cdots \\
H
\end{array}\right]=-\left[A_{10} H_{0}\right]-\left[A_{10} \varphi_{H_{0}}\right]
$$


where:

- $A_{11 \varphi}$ is a $(p \times p)$ diagonal matrix. Each element refers to one network pipe $(r)$ that connects two nodes $(i j)$ :

$$
A_{11 \varphi}(r, r)=\vartheta_{\mathrm{ij}} \mathrm{r}_{\mathrm{ij}}\left(2\left|\mathrm{Q}_{i j_{0}}\right|+\frac{\mathrm{Q}_{i j_{0}}}{\left|\mathrm{Q}_{i j_{0}}\right|} \varphi_{Q_{i j}}\right)
$$

- $A_{11 \vartheta}$ is a $(p \times p)$ diagonal matrix. Each element refers to one network pipe $(r)$ that connects two nodes $(i j)$ :

$$
A_{11 \vartheta}(r, r)=\vartheta_{\mathrm{ij}} \mathrm{r}_{\mathrm{ij}}\left|\mathrm{Q}_{i j_{0}}\right|
$$

- $H$ is the vector of the node heads $H_{i_{0}}$

- $\varphi_{H}$ is the vector of the node head average sensitivities $\varphi_{H_{i}}$

- $A_{10}$ is a matrix that relates pipes to fixed head nodes.

- $H_{0}$ is the vector of the heads for the fixed head nodes.

- $\varphi_{H_{0}}$ is the vector of the head average sensitivities for the fixed head nodes, whose elements are, in fact, zeros.

- $\varphi_{Q}, Q, q, \frac{\varphi_{q}}{n}$ and $A_{21}$ are the vectors and matrix explained above.

- $A_{12}=A_{21}{ }^{T}$

Equation A19 can be operated to:

$$
\left[\begin{array}{lll}
A_{11 \varphi} & \vdots & A_{12}
\end{array}\right]\left[\begin{array}{c}
\varphi_{Q} \\
\cdots \\
\varphi_{H}
\end{array}\right]=-\left[\begin{array}{lll}
A_{11 \vartheta} & \vdots & A_{12}
\end{array}\right]\left[\begin{array}{c}
Q \\
\cdots \\
H
\end{array}\right]-\left[A_{10} H_{0}\right]
$$

The complete system of conservation equations can be obtained by merging System A9 and System A20. The new system consists of $(n+p)$ equations, with $(n+p)$ unknowns, and it can take a matrix formulation like:

$$
\left[\begin{array}{ccc}
A_{11 \varphi} & \vdots & A_{12} \\
\cdots & \cdots & \cdots \\
A_{21} & \vdots & 0
\end{array}\right]\left[\begin{array}{c}
\varphi_{Q} \\
\cdots \\
\varphi_{H}
\end{array}\right]=-\left[\begin{array}{ccc}
A_{11 \vartheta} & \vdots & A_{12} \\
\cdots & \cdots & \cdots \\
A_{21} & \vdots & 0
\end{array}\right]\left[\begin{array}{c}
Q \\
\cdots \\
H
\end{array}\right]-\left[\begin{array}{c}
A_{10} H_{0} \\
\cdots \\
q+\frac{\varphi_{q}}{n}
\end{array}\right]
$$

Being $\varphi_{Q}$ and $\varphi_{H}$ the vectors of the unknown factors, System A21 can be solved through the Newton-Raphson method to finally obtain the sensitivities for each node and pipe in the network. 


\section{Appendix B. Development of equations for leak location}

If there is a leak in the network whose location is unknown, then a (also unknown) possible leak flowrate is considered in each node $q_{i_{L}}$. The flowrate in each network node will be the addition to the usual demand $q_{i}$, plus the potential leak $q_{i_{L}}$.

Because of the disturbance that the leak introduces into the network operating conditions, each pipe flowrate in the (new) leak scenario $Q_{i j_{L}}$ will likely be different from the usual value in the (reference) no-leak scenario $Q_{i j_{0}}$.

Therefore, the mass conservation equation for each node $i$ in the leak scenario is:

$$
\sum_{k=1}^{n_{i}} Q_{i k_{L}}+q_{i}+q_{i_{L}}=0
$$

where $n_{i}$ is the total number of nodes connected to node $i, Q_{i k_{L}}$ is the new circulating flowrate through the pipe that connects node $i$ to node $k, q_{i}$ is the demand flowrate at node $i$, and $q_{i_{L}}$ is the potential leak flowrate at node $i$.

By following the same procedure explained in Appendix A, the system of $n$ mass conservation equations (one equation for each node) can be expressed as:

$$
\left[\begin{array}{lll}
A_{21} & \vdots & 1
\end{array}\right]\left[\begin{array}{c}
Q_{L} \\
\cdots \\
q_{L}
\end{array}\right]=-\left[A_{21} Q_{D}\right]-[q]
$$

where:

- $Q_{L}$ is the vector of the pipe flowrates $Q_{i j_{L}}$ that are unknown. In principle, all the pipe flowrates are unknown, but if there are some flowmeters installed in some pipes, the data they provide will be known pipe flowrates, then their corresponding values in $Q_{L}$ will be set to zero.

- $q_{L}$ is the vector of the node potential leak flowrates $q_{i_{L}}$

- $Q_{D}$ is the vector of the pipe flowrates $Q_{i j_{L}}$ that are known. Known flow measures provided by possible flowmeters in the network are included in their corresponding elements in vector $Q_{D}$, being zero the rest of elements.

- $A_{21}$ and $q$ are explained in Appendix A.

System B2 is compounded by $n$ equations, being $(n+p)$ the highest possible number of unknowns. The total number of unknowns would be reduced in the same quantity as flowmeters were installed in the network.

The energy conservation equation for each pipe, which connects node $i$ to node $j$, in the leak scenario is:

$$
H_{i_{L}}-H_{j_{L}}=r_{i j} Q_{i j_{L}}\left|Q_{i j_{L}}\right|
$$


which can be expressed:

$$
\left[\begin{array}{lll}
A_{11} & \vdots & A_{12}
\end{array}\right]\left[\begin{array}{c}
Q_{L} \\
\ldots \\
H_{L}
\end{array}\right]=-\left[A_{10} H_{0}\right]
$$

where $H_{L}$ is the vector of the node heads $H_{i_{L}}, Q_{L}$ is explained above, and $A_{11}, A_{12}, A_{10}$ and $H_{0}$ are explained in Appendix A

As explained in the case of the mass conservation equation, if some flowmeters are installed in the network, not all the pipe flowrates will be unknown. Being $\left[Q_{D}\right]$ the vector of known pipe flowrates, System B4 can be written as:

$$
\left[\begin{array}{lll}
A_{11} & \vdots & A_{12}
\end{array}\right]\left[\begin{array}{c}
Q_{L} \\
\ldots \\
H_{L}
\end{array}\right]=-\left[\begin{array}{ll}
A_{11} & Q_{D}
\end{array}\right]-\left[A_{10} H_{0}\right]
$$

In principle, node heads in the leak scenario $H_{i_{L}}$ are unknown, but:

- If there are pressure sensors installed in some nodes, the data they provide are known values for some node pressures.

- For the rest of the nodes, not being monitored by a preassure sensor, their head could be approximated by taking into account the average sensitivity (as calculated in Appendix A): $H_{i_{L}}=H_{i_{0}}+\varphi_{H_{i}}$

Therefore, the node heads in the leak scenario can be considered as known (or approximated), vector $H_{L}$ is renamed as $H_{D}$, and it can be shifted to the right hand side of the equation:

$$
\left[A_{11} Q_{L}\right]=-\left[A_{11} Q_{D}\right]-\left[A_{12} H_{D}\right]-\left[A_{10} H_{0}\right]
$$

The complete system of conservation equations for the leak scenario can be obtained by merging System B2 and System B6:

$$
\left[\begin{array}{ccc}
A_{11} & \vdots & 0 \\
\cdots & \cdots & \cdots \\
A_{21} & \vdots & 1
\end{array}\right]\left[\begin{array}{c}
Q_{L} \\
\cdots \\
q_{L}
\end{array}\right]=-\left[\begin{array}{ccc}
A_{11} & \vdots & A_{12} \\
\cdots & \cdots & \cdots \\
A_{21} & \vdots & 0
\end{array}\right]\left[\begin{array}{c}
Q_{D} \\
\cdots \\
H_{D}
\end{array}\right]-\left[\begin{array}{c}
A_{10} H_{0} \\
\cdots \\
q
\end{array}\right]
$$

The new System B7 is compounded by $(n+p)$ equations, and the maximum number of unknowns would be $(n+p)$ - for the case in which no flowmeters are installed in the network. If some flowmeters are installed, the total number of unknowns would be reduced by the same quantity as flowmeters installed.

Being $Q_{L}$ and $q_{L}$ the vectors of the unknown factors, System B7 can be solved using the NewtonRaphson method to obtain the potential leak flowrates $q_{L}$ for each node in the network. 


\section{Appendix C. Full information about the network of the case study}

For reasons of confidentiality, the study case uses a synthetic rather than real network. Nevertheless, the network is a direct adaptation of a network in the region of Valencia (Spain) that is managed by the first author of this paper.

Table C1. Physical characteristics and normal operation values for pipe variables

\begin{tabular}{|c|c|c|c|c|}
\hline $\begin{array}{c}\text { Pipe } \\
\text { ID }\end{array}$ & $\begin{array}{c}\varnothing \\
(\mathrm{mm})\end{array}$ & $\begin{array}{c}\text { Length } \\
(\mathrm{m})\end{array}$ & $\begin{array}{c}\text { Velocity } \\
(\mathrm{m} / \mathrm{s})\end{array}$ & $\begin{array}{c}\text { Unit. } \\
\text { Headloss } \\
(\mathrm{m} / \mathrm{km})\end{array}$ \\
\hline 1 & 200 & 977.3 & 1.22 & 7.13 \\
\hline 2 & 150 & 1629.5 & 0.31 & 0.79 \\
\hline 3 & 100 & 559.4 & 0.73 & 6.41 \\
\hline 4 & 100 & 1021.6 & 0.14 & 0.33 \\
\hline 5 & 100 & 1624.3 & 0.46 & 2.74 \\
\hline 6 & 50 & 1862.8 & 0.22 & 1.69 \\
\hline 7 & 200 & 428.1 & 1.20 & 6.92 \\
\hline 8 & 200 & 1838.5 & 0.71 & 2.56 \\
\hline 9 & 200 & 986.9 & 0.62 & 1.96 \\
\hline 10 & 150 & 987.9 & 0.70 & 3.53 \\
\hline 11 & 100 & 481.3 & 0.92 & 9.95 \\
\hline 12 & 100 & 510.8 & 0.57 & 3.95 \\
\hline 13 & 100 & 432.7 & 0.15 & 0.35 \\
\hline 14 & 150 & 461.7 & 0.50 & 1.90 \\
\hline 15 & 90 & 467.7 & 0.58 & 4.75 \\
\hline 16 & 90 & 1830.3 & 0.11 & 0.23 \\
\hline 17 & 90 & 447.1 & 0.36 & 1.97 \\
\hline 18 & 90 & 464.2 & 0.83 & 9.32 \\
\hline 19 & 200 & 471.8 & 0.45 & 1.11 \\
\hline 20 & 200 & 482.7 & 0.50 & 1.31 \\
\hline 21 & 200 & 520.3 & 0.60 & 1.85 \\
\hline 22 & 100 & 486.6 & 0.57 & 4.05 \\
\hline 23 & 100 & 496.0 & 0.49 & 2.97 \\
\hline 24 & 90 & 461.7 & 0.49 & 3.49 \\
\hline 25 & 90 & 473.4 & 0.34 & 1.72 \\
\hline 26 & 90 & 471.8 & 0.17 & 0.49 \\
\hline 27 & 50 & 1625.4 & 0.03 & 0.06 \\
\hline 28 & 90 & 568.8 & 0.57 & 4.56 \\
\hline 29 & 90 & 469.1 & 0.21 & 0.72 \\
\hline
\end{tabular}

\begin{tabular}{|c|c|c|c|c|}
\hline $\begin{array}{c}\text { Pipe } \\
\text { ID }\end{array}$ & $\begin{array}{c}\varnothing \\
(\mathrm{mm})\end{array}$ & $\begin{array}{c}\text { Length } \\
(\mathrm{m})\end{array}$ & $\begin{array}{c}\text { Velocity } \\
(\mathrm{m} / \mathrm{s})\end{array}$ & $\begin{array}{c}\text { Unit. } \\
\text { Headloss } \\
(\mathrm{m} / \mathrm{km})\end{array}$ \\
\hline 30 & 90 & 498.5 & 0.28 & 1.21 \\
\hline 31 & 90 & 426.1 & 0.51 & 3.72 \\
\hline 32 & 50 & 471.4 & 0.52 & 8.04 \\
\hline 33 & 50 & 1634.9 & 0.16 & 0.95 \\
\hline 34 & 50 & 775.2 & 0.43 & 5.78 \\
\hline 35 & 50 & 1648.6 & 0.16 & 1.00 \\
\hline 36 & 200 & 496.0 & 0.83 & 3.42 \\
\hline 37 & 200 & 476.3 & 0.76 & 2.91 \\
\hline 38 & 200 & 482.7 & 0.72 & 2.61 \\
\hline 39 & 90 & 437.4 & 0.70 & 6.73 \\
\hline 40 & 90 & 512.6 & 0.15 & 0.39 \\
\hline 41 & 150 & 1064.9 & 0.15 & 0.20 \\
\hline 42 & 150 & 497.6 & 0.10 & 0.11 \\
\hline 43 & 50 & 485.2 & 0.01 & 0.01 \\
\hline 44 & 50 & 1652.9 & 0.04 & 0.08 \\
\hline 45 & 200 & 1012.2 & 0.54 & 1.55 \\
\hline 46 & 50 & 699.9 & 0.04 & 0.09 \\
\hline 47 & 50 & 797.1 & 0.08 & 0.28 \\
\hline 48 & 90 & 501.4 & 0.59 & 4.94 \\
\hline 49 & 90 & 456.9 & 0.15 & 0.39 \\
\hline 50 & 90 & 496.0 & 0.22 & 0.77 \\
\hline 51 & 200 & 593.2 & 0.29 & 0.48 \\
\hline 52 & 50 & 490.9 & 0.50 & 7.61 \\
\hline 53 & 150 & 1652.9 & 0.12 & 0.15 \\
\hline 54 & 200 & 1608.8 & 0.15 & 0.15 \\
\hline 55 & 90 & 1606.6 & 0.10 & 0.18 \\
\hline 56 & 50 & 1860.0 & 0.09 & 0.36 \\
\hline 57 & 50 & 1843.8 & 0.17 & 1.11 \\
\hline 58 & 150 & 1841.2 & 0.34 & 0.91 \\
\hline
\end{tabular}


Table C2. Node sensitivity analysis

\begin{tabular}{|c|c|c|c|c|c|c|c|}
\hline \multirow{3}{*}{$\begin{array}{c}\text { Node } \\
\text { id } \\
1\end{array}$} & \multirow{3}{*}{$\begin{array}{c}\begin{array}{c}\text { Initial } \\
\text { pressure } \\
\text { (mwc) }\end{array} \\
41.75\end{array}$} & \multicolumn{6}{|c|}{ Pressure variation (mwc) } \\
\hline & & \multicolumn{2}{|c|}{$\begin{array}{c}\text { Increase of } \\
15 \mathrm{lpm}\end{array}$} & \multicolumn{2}{|c|}{$\begin{array}{c}\text { Increase of } \\
30 \mathrm{lpm}\end{array}$} & \multicolumn{2}{|c|}{$\begin{array}{l}\text { Increase of } \\
60 \mathrm{lpm}\end{array}$} \\
\hline & & -0.07 & $-0.17 \%$ & -0.13 & $-0.31 \%$ & -0.26 & $-0.62 \%$ \\
\hline 2 & 39.78 & -0.09 & $-0.23 \%$ & -0.17 & $-0.43 \%$ & -0.34 & $-0.85 \%$ \\
\hline 3 & 38.30 & -0.10 & $-0.26 \%$ & -0.20 & $-0.52 \%$ & -0.40 & $-1.04 \%$ \\
\hline 4 & 36.69 & -0.11 & $-0.30 \%$ & -0.23 & $-0.63 \%$ & -0.45 & $-1.23 \%$ \\
\hline 5 & 35.88 & -0.12 & $-0.33 \%$ & -0.24 & $-0.67 \%$ & -0.47 & $-1.31 \%$ \\
\hline 6 & 35.65 & -0.12 & $-0.34 \%$ & -0.24 & $-0.67 \%$ & -0.48 & $-1.35 \%$ \\
\hline 7 & 35.55 & -0.11 & $-0.31 \%$ & -0.21 & $-0.59 \%$ & -0.42 & $-1.18 \%$ \\
\hline 8 & 35.75 & -0.10 & $-0.28 \%$ & -0.20 & $-0.56 \%$ & -0.41 & $-1.15 \%$ \\
\hline 9 & 38.69 & -0.08 & $-0.21 \%$ & -0.16 & $-0.41 \%$ & -0.32 & $-0.83 \%$ \\
\hline 10 & 39.95 & -0.07 & $-0.18 \%$ & -0.14 & $-0.35 \%$ & -0.29 & $-0.73 \%$ \\
\hline 11 & 41.33 & -0.06 & $-0.15 \%$ & -0.13 & $-0.31 \%$ & -0.25 & $-0.60 \%$ \\
\hline 12 & 43.03 & -0.05 & $-0.12 \%$ & -0.10 & $-0.23 \%$ & -0.21 & $-0.49 \%$ \\
\hline 13 & 39.44 & -0.07 & $-0.18 \%$ & -0.15 & $-0.38 \%$ & -0.30 & $-0.76 \%$ \\
\hline 14 & 39.11 & -0.08 & $-0.20 \%$ & -0.15 & $-0.38 \%$ & -0.31 & $-0.79 \%$ \\
\hline 15 & 43.55 & -0.04 & $-0.09 \%$ & -0.09 & $-0.21 \%$ & -0.17 & $-0.39 \%$ \\
\hline 16 & 40.40 & -0.06 & $-0.15 \%$ & -0.12 & $-0.30 \%$ & -0.25 & $-0.62 \%$ \\
\hline 17 & 36.85 & -0.09 & $-0.24 \%$ & -0.17 & $-0.46 \%$ & -0.35 & $-0.95 \%$ \\
\hline 18 & 36.63 & -0.09 & $-0.25 \%$ & -0.18 & $-0.49 \%$ & -0.35 & $-0.96 \%$ \\
\hline 19 & 38.76 & -0.07 & $-0.18 \%$ & -0.15 & $-0.39 \%$ & -0.29 & $-0.75 \%$ \\
\hline
\end{tabular}

\begin{tabular}{|c|c|c|c|c|c|c|c|}
\hline \multirow{3}{*}{$\begin{array}{c}\begin{array}{c}\text { Node } \\
\text { id }\end{array} \\
20\end{array}$} & \multirow{3}{*}{$\begin{array}{c}\begin{array}{c}\text { Initial } \\
\text { pressure } \\
(\mathrm{mwc})\end{array} \\
39.43\end{array}$} & \multicolumn{6}{|c|}{ Pressure variation (mwc) } \\
\hline & & \multicolumn{2}{|c|}{$\begin{array}{c}\text { Increase of } \\
15 \mathrm{lpm}\end{array}$} & \multicolumn{2}{|c|}{$\begin{array}{c}\text { Increase of } \\
30 \mathrm{lpm}\end{array}$} & \multicolumn{2}{|c|}{$\begin{array}{l}\text { Increase of } \\
60 \mathrm{lpm}\end{array}$} \\
\hline & & -0.07 & $-0.18 \%$ & -0.14 & $-0.36 \%$ & -0.26 & $-0.66 \%$ \\
\hline 21 & 38.80 & -0.09 & $-0.23 \%$ & -0.15 & $-0.39 \%$ & -0.34 & $-0.88 \%$ \\
\hline 22 & 36.75 & -0.10 & $-0.27 \%$ & -0.17 & $-0.46 \%$ & -0.40 & $-1.09 \%$ \\
\hline 23 & 36.45 & -0.11 & $-0.30 \%$ & -0.18 & $-0.49 \%$ & -0.45 & $-1.23 \%$ \\
\hline 24 & 36.52 & -0.12 & $-0.33 \%$ & -0.18 & $-0.49 \%$ & -0.47 & $-1.29 \%$ \\
\hline 25 & 37.12 & -0.12 & $-0.32 \%$ & -0.17 & $-0.46 \%$ & -0.48 & $-1.29 \%$ \\
\hline 26 & 35.53 & -0.11 & $-0.31 \%$ & -0.20 & $-0.56 \%$ & -0.42 & $-1.18 \%$ \\
\hline 27 & 31.74 & -0.10 & $-0.32 \%$ & -0.31 & $-0.98 \%$ & -0.41 & $-1.29 \%$ \\
\hline 28 & 36.83 & -0.08 & $-0.22 \%$ & -0.18 & $-0.49 \%$ & -0.32 & $-0.87 \%$ \\
\hline 29 & 35.48 & -0.07 & $-0.20 \%$ & -0.20 & $-0.56 \%$ & -0.29 & $-0.82 \%$ \\
\hline 30 & 31.74 & -0.06 & $-0.19 \%$ & -0.31 & $-0.98 \%$ & -0.25 & $-0.79 \%$ \\
\hline 31 & 33.50 & -0.05 & $-0.15 \%$ & -0.21 & $-0.63 \%$ & -0.21 & $-0.63 \%$ \\
\hline 32 & 35.72 & -0.07 & $-0.20 \%$ & -0.19 & $-0.53 \%$ & -0.30 & $-0.84 \%$ \\
\hline 33 & 36.60 & -0.08 & $-0.22 \%$ & -0.18 & $-0.49 \%$ & -0.31 & $-0.85 \%$ \\
\hline 34 & 38.28 & -0.04 & $-0.10 \%$ & -0.15 & $-0.39 \%$ & -0.17 & $-0.44 \%$ \\
\hline 35 & 33.96 & -0.06 & $-0.18 \%$ & -0.20 & $-0.59 \%$ & -0.25 & $-0.74 \%$ \\
\hline 36 & 33.08 & -0.09 & $-0.27 \%$ & -0.21 & $-0.63 \%$ & -0.35 & $-1.06 \%$ \\
\hline 37 & 42.33 & -0.09 & $-0.21 \%$ & -0.10 & $-0.24 \%$ & -0.35 & $-0.83 \%$ \\
\hline 38 & 47.04 & -0.07 & $-0.15 \%$ & -0.04 & $-0.09 \%$ & -0.29 & $-0.62 \%$ \\
\hline
\end{tabular}


Table C3. Pipe sensitivity analysis

\begin{tabular}{|c|c|c|c|c|c|c|c|}
\hline \multirow{3}{*}{$\begin{array}{c}\text { Line } \\
\text { id } \\
1\end{array}$} & \multirow{3}{*}{\begin{tabular}{|c}
$\begin{array}{c}\text { Initial } \\
\text { flow } \\
\text { (L/minute) }\end{array}$ \\
2298.28
\end{tabular}} & \multicolumn{6}{|c|}{ Flow variation } \\
\hline & & \multicolumn{2}{|c|}{$\begin{array}{c}\text { Increase of } \\
15 \\
\text { (L/minute) } \\
\end{array}$} & \multicolumn{2}{|c|}{$\begin{array}{c}\text { Increase of } \\
30 \\
\text { (L/minute) } \\
\end{array}$} & \multicolumn{2}{|c|}{$\begin{array}{c}\text { Increase of } \\
60 \\
\text { (L/minute) } \\
\end{array}$} \\
\hline & & 8.01 & $0.35 \%$ & 16.02 & $0.70 \%$ & 32.04 & $1.39 \%$ \\
\hline 2 & 330.18 & 1.64 & $0.50 \%$ & 3.27 & $0.99 \%$ & 6.53 & $1.98 \%$ \\
\hline 3 & 345.39 & 1.05 & $0.30 \%$ & 2.1 & $0.61 \%$ & 4.2 & $1.22 \%$ \\
\hline 4 & 68.12 & 0.15 & $0.22 \%$ & 0.31 & $0.46 \%$ & 0.61 & $0.90 \%$ \\
\hline 5 & 218.79 & 0.77 & $0.35 \%$ & 1.53 & $0.70 \%$ & 3.06 & $1.40 \%$ \\
\hline 6 & 25.85 & 0.08 & $0.31 \%$ & 0.15 & $0.58 \%$ & 0.31 & $1.20 \%$ \\
\hline 7 & 2261.72 & 6.99 & $0.31 \%$ & 13.98 & $0.62 \%$ & 27.96 & $1.24 \%$ \\
\hline 8 & 1341.27 & 4.11 & $0.31 \%$ & 8.22 & $0.61 \%$ & 16.44 & $1.23 \%$ \\
\hline 9 & 1161.27 & 3.71 & $0.32 \%$ & 7.43 & $0.64 \%$ & 14.86 & $1.28 \%$ \\
\hline 10 & 740.45 & 2.49 & $0.34 \%$ & 4.97 & $0.67 \%$ & 9.94 & $1.34 \%$ \\
\hline 11 & 435.81 & 1.25 & $0.29 \%$ & 2.5 & $0.57 \%$ & 4.99 & $1.14 \%$ \\
\hline 12 & 266.51 & 0.89 & $0.33 \%$ & 1.78 & $0.67 \%$ & 3.56 & $1.34 \%$ \\
\hline 13 & 70.17 & 0.44 & $0.63 \%$ & 0.87 & $1.24 \%$ & 1.75 & $2.49 \%$ \\
\hline 14 & 531.57 & 1.91 & $0.36 \%$ & 3.82 & $0.72 \%$ & 7.65 & $1.44 \%$ \\
\hline 15 & 221.97 & 0.4 & $0.18 \%$ & 0.8 & $0.36 \%$ & 1.59 & $0.72 \%$ \\
\hline 16 & 41.97 & 0 & $0.00 \%$ & 0.01 & $0.02 \%$ & 0.01 & $0.02 \%$ \\
\hline 17 & 138.03 & 0.39 & $0.28 \%$ & 0.78 & $0.57 \%$ & 1.57 & $1.14 \%$ \\
\hline 18 & 318.03 & 0.79 & $0.25 \%$ & 1.57 & $0.49 \%$ & 3.15 & $0.99 \%$ \\
\hline 19 & 855.99 & 2.5 & $0.29 \%$ & 5 & $0.58 \%$ & 10.01 & $1.17 \%$ \\
\hline 20 & 936.42 & 2.97 & $0.32 \%$ & 5.93 & $0.63 \%$ & 11.87 & $1.27 \%$ \\
\hline 21 & 1127.12 & 3.4 & $0.30 \%$ & 6.79 & $0.60 \%$ & 13.59 & $1.21 \%$ \\
\hline 22 & 270.18 & 1.24 & $0.46 \%$ & 2.48 & $0.92 \%$ & 4.95 & $1.83 \%$ \\
\hline 23 & 228.87 & 0.97 & $0.42 \%$ & 1.94 & $0.85 \%$ & 3.87 & $1.69 \%$ \\
\hline 24 & 188.08 & 0.73 & $0.39 \%$ & 1.45 & $0.77 \%$ & 2.87 & $1.53 \%$ \\
\hline 25 & 128.08 & 0.33 & $0.26 \%$ & 0.66 & $0.52 \%$ & 1.29 & $1.01 \%$ \\
\hline 26 & 63.74 & 0.18 & $0.28 \%$ & 0.36 & $0.56 \%$ & 0.72 & $1.13 \%$ \\
\hline 27 & 3.74 & -0.21 & $-5.61 \%$ & -0.43 & $-11.5 \%$ & -0.86 & $-23.0 \%$ \\
\hline 28 & 217.27 & 0.5 & $0.23 \%$ & 1 & $0.46 \%$ & 2 & $0.92 \%$ \\
\hline 29 & 78.98 & 0.22 & $0.28 \%$ & 0.43 & $0.54 \%$ & 0.87 & $1.10 \%$ \\
\hline
\end{tabular}

\begin{tabular}{|c|c|c|c|c|c|c|c|}
\hline \multirow{3}{*}{$\begin{array}{c}\text { Line } \\
\text { id } \\
30\end{array}$} & \multirow{3}{*}{$\begin{array}{c}\begin{array}{c}\text { Initial } \\
\text { flow } \\
\text { (L/minute) }\end{array} \\
105.77\end{array}$} & \multicolumn{6}{|c|}{ Flow variation } \\
\hline & & \multicolumn{2}{|c|}{$\begin{array}{c}\text { Increase of } \\
15 \\
\text { (L/minute) } \\
\end{array}$} & \multicolumn{2}{|c|}{$\begin{array}{c}\text { Increase of } \\
30 \\
\text { (L/minute) } \\
\end{array}$} & \multicolumn{2}{|c|}{$\begin{array}{c}\text { Increase of } \\
60 \\
\text { (L/minute) } \\
\end{array}$} \\
\hline & & 0.18 & $0.17 \%$ & 0.36 & $0.34 \%$ & 0.72 & $0.68 \%$ \\
\hline 31 & 194.82 & 0.77 & $0.40 \%$ & 1.55 & $0.80 \%$ & 3.1 & $1.59 \%$ \\
\hline 32 & 60.88 & 0.4 & $0.66 \%$ & 0.79 & $1.30 \%$ & 1.59 & $2.61 \%$ \\
\hline 33 & 18.69 & 0.13 & $0.70 \%$ & 0.25 & $1.34 \%$ & 0.5 & $2.68 \%$ \\
\hline 34 & 50.92 & 0.13 & $0.26 \%$ & 0.27 & $0.53 \%$ & 0.53 & $1.04 \%$ \\
\hline 35 & 19.21 & 0.15 & $0.78 \%$ & 0.29 & $1.51 \%$ & 0.58 & $3.02 \%$ \\
\hline 36 & 1562.71 & 4.93 & $0.32 \%$ & 9.86 & $0.63 \%$ & 19.74 & $1.26 \%$ \\
\hline 37 & 1433.10 & 4.28 & $0.30 \%$ & 8.56 & $0.60 \%$ & 17.13 & $1.20 \%$ \\
\hline 38 & 1353.88 & 3.74 & $0.28 \%$ & 7.48 & $0.55 \%$ & 14.97 & $1.11 \%$ \\
\hline 39 & 267.49 & 0.94 & $0.35 \%$ & 1.87 & $0.70 \%$ & 3.76 & $1.41 \%$ \\
\hline 40 & 56.26 & 0.61 & $1.08 \%$ & 1.22 & $2.17 \%$ & 2.44 & $4.34 \%$ \\
\hline 41 & 155.58 & -0.31 & $-0.20 \%$ & -0.63 & $-0.40 \%$ & -1.27 & $-0.82 \%$ \\
\hline 42 & 109.52 & -0.33 & $-0.30 \%$ & -0.66 & $-0.60 \%$ & -1.33 & $-1.21 \%$ \\
\hline 43 & 0.88 & 0 & $0.00 \%$ & 0 & $0.00 \%$ & 0.01 & $1.14 \%$ \\
\hline 44 & 4.34 & -0.24 & $-5.53 \%$ & -0.49 & $-11.3 \%$ & -1.01 & $-23.3 \%$ \\
\hline 45 & 1026.39 & 2.4 & $0.23 \%$ & 4.81 & $0.47 \%$ & 9.63 & $0.94 \%$ \\
\hline 46 & 4.75 & 0 & $0.00 \%$ & 0.01 & $0.21 \%$ & 0.01 & $0.21 \%$ \\
\hline 47 & 9.21 & 0.02 & $0.22 \%$ & 0.04 & $0.43 \%$ & 0.09 & $0.98 \%$ \\
\hline 48 & 226.91 & 0.52 & $0.23 \%$ & 1.05 & $0.46 \%$ & 2.1 & $0.93 \%$ \\
\hline 49 & 56.12 & 0.15 & $0.27 \%$ & 0.3 & $0.53 \%$ & 0.6 & $1.07 \%$ \\
\hline 50 & 82.35 & 0.11 & $0.13 \%$ & 0.23 & $0.28 \%$ & 0.45 & $0.55 \%$ \\
\hline 51 & 545.79 & 1.06 & $0.19 \%$ & 2.11 & $0.39 \%$ & 4.23 & $0.78 \%$ \\
\hline 52 & 59.12 & 0.39 & $0.66 \%$ & 0.79 & $1.34 \%$ & 1.57 & $2.66 \%$ \\
\hline 53 & 129.60 & 1.12 & $0.86 \%$ & 2.24 & $1.73 \%$ & 4.48 & $3.46 \%$ \\
\hline 54 & 283.45 & 0.55 & $0.19 \%$ & 1.1 & $0.39 \%$ & 2.2 & $0.78 \%$ \\
\hline 55 & 36.78 & 0.13 & $0.35 \%$ & 0.25 & $0.68 \%$ & 0.51 & $1.39 \%$ \\
\hline 56 & 10.70 & 0.03 & $0.28 \%$ & 0.07 & $0.65 \%$ & 0.14 & $1.31 \%$ \\
\hline 57 & 20.43 & 0.07 & $0.34 \%$ & 0.14 & $0.69 \%$ & 0.28 & $1.37 \%$ \\
\hline 58 & 357.96 & 1.32 & $0.37 \%$ & 2.64 & $0.74 \%$ & 5.28 & $1.48 \%$ \\
\hline
\end{tabular}




\section{Appendix D. Leak location solutions for various installations of pressure sensors and flowmeters}

Table D1. Summary table for the various sensor configurations tested in the case study

\begin{tabular}{|l|c|c|c|c|c|c|c|}
\hline & Config. 1 & Config. 2 & Config. 3 & Config. 4 & Config. 5 & Config. 6 & Config. 7 \\
\hline \# Pressure sensors & 5 & 5 & 5 & 10 & 10 & 15 & 15 \\
\hline \# Flowmeters & 5 & 5 & 5 & 0 & 5 & 0 & 5 \\
\hline Total cases & 38 & 38 & 38 & 38 & 38 & 38 & 38 \\
\hline Detection of node & 8 & 8 & 9 & 10 & 10 & 15 & 16 \\
\hline Detection of area & 16 & 8 & 10 & 10 & 13 & 15 & 17 \\
\hline No detection & 14 & 22 & 19 & 18 & 15 & 8 & 5 \\
\hline Successful cases & 24 & 16 & 19 & 20 & 23 & 30 & 33 \\
\hline Success rate & $63 \%$ & $42 \%$ & $50 \%$ & $53 \%$ & $61 \%$ & $79 \%$ & $87 \%$ \\
\hline
\end{tabular}

This table shows both the number and type of sensors. Configurations 1 to 3 show the influence of the position of the sensors according to the criteria of node sensitivity and spatial distribution. The results show that the first criterion has a greater weight on the success rate than the second. Configurations 4 to 7 explore the influence of the number of sensors used. It is clear that with a maximum of 20 sensors (out of a total of 96 elements) the success rate nealry reaches $90 \%$. The detailed results for each configuration are shown in the following tables. 
Table D2. Leak flows obtained with 5 pressure sensors and 5 flowmeters installed by combining criteria on highest sensitivity and spatial distribution (nodes 5, 18, 27, 30, 37 and pipes 1, 9, 20, 36, 45)

\begin{tabular}{|c|c|c|c|c|c|c|c|c|c|c|c|c|c|c|c|c|c|c|c|c|c|c|c|c|c|c|c|c|c|c|c|c|c|c|c|c|c|c|}
\hline & 1 & 2 & 3 & 4 & 5 & 6 & 7 & 8 & & 10 & 11 & 12 & 13 & 14 & 15 & 16 & 17 & 18 & 19 & 20 & 21 & 22 & 23 & 24 & 25 & 26 & 27 & 28 & 29 & 30 & 31 & 32 & 33 & 34 & 35 & 36 & 37 & \\
\hline & 1.0 & 1.0 & 1.0 & 1.0 & 1.0 & 1.0 & 1.0 & 1.0 & 1.0 & 1.0 & 1.0 & 1.0 & 1.0 & 1.0 & 1.0 & 1.0 & \begin{tabular}{|l|l}
1.0 \\
\end{tabular} & \begin{tabular}{|l|l}
1.0 \\
\end{tabular} & 1.0 & 1.0 & \begin{tabular}{|l|l}
1.0 \\
\end{tabular} & 1.0 & \begin{tabular}{|l|l}
1.0 \\
\end{tabular} & 1.0 & 1.0 & 1.0 & 1.0 & 1.0 & 1.0 & $\begin{array}{ll}1.0 \\
\end{array}$ & $\mid 1.0$ & 1.0 & 1.0 & 1.0 & 1.0 & 1.0 & 1.0 & 1.0 \\
\hline & 0.9 & 0.9 & 0.9 & 0.9 & 0.9 & 0.9 & 0.9 & 0.9 & 0.9 & 0.9 & 0.9 & 0.9 & 0.9 & 0.9 & 0.9 & 0.9 & 0.9 & 0.9 & 0.9 & 0.9 & 0.9 & 0.9 & 0.9 & 0.9 & 0.9 & 0.9 & 0.9 & 0.9 & 0.9 & 0.9 & 0.9 & 0.9 & 0.9 & 0.9 & 0.9 & 0.9 & 0.9 & 09 \\
\hline & 0.9 & 0.9 & 0.9 & 0.9 & 0.9 & 0.9 & 0.9 & 0.9 & 0.9 & 0.9 & 0.9 & 0.9 & 0.9 & 0.9 & 0.9 & 0.9 & 0.9 & 0.9 & 0.9 & 0.9 & 0.9 & 0.9 & 0.9 & 0.9 & 0.9 & 0.9 & 0.9 & \begin{tabular}{l|l}
0.9 \\
\end{tabular} & 0.9 & \begin{tabular}{|l|}
0.9 \\
\end{tabular} & 0.9 & 0.9 & 0.9 & 0.9 & 0.9 & 0.9 & 0.9 & 0.9 \\
\hline & 6.1 & $\begin{array}{l}-3 \\
\end{array}$ & $\begin{array}{l}-9 \\
\end{array}$ & -22 & -32 & -28 & -5 & 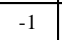 & 7.5 & 8.6 & 10.0 & 11.8 & 10.6 & \begin{tabular}{|l|l}
10.9 \\
\end{tabular} & 16.3 & 13.8 & 8.7 & 8.6 & 11.4 & 12.8 & 12.0 & 8.1 & 8.1 & 8.1 & 7.1 & 1.7 & 2.0 & 7.2 & 2.3 & 2.0 & 6.6 & 5.0 & & & & & 15. & 19.9 \\
\hline 5 & -14.2 & 12.6 & 38.2 & 125.4 & 167.6 & 153.8 & 22.3 & 6.7 & -18.0 & -20.8 & -24.5 & -29.3 & -26.3 & $\mid$ & -40.5 & -34.2 & -21.2 & -21.1 & $\mid-28.2$ & $\mid-31.7$ & $\mid-29.8$ & -19.5 & 19.6 & 19. & 16.8 & -1.4 & -2.2 & 17.1 & -3.3 & -2.4 & 15. & 10. & -17.1 & 28.1 & 22. & 19.8 & -39.0 & -49.0 \\
\hline 6 & 9.9 & -5.8 & -20.8 & -91.3 & -121 & -112 & -11.6 & -2.2 & 12.0 & 13.6 & \begin{tabular}{|l|l}
15.6 \\
\end{tabular} & 18.2 & \begin{tabular}{|ll}
16.6 \\
\end{tabular} & 17.0 & 24.2 & 20.9 & 13.8 & 3.7 & 17.7 & 19.5 & 18.5 & 12.9 & 12.9 & 2.9 & 1.3 & 2.5 & 3.0 & 1.5 & 3.7 & 3.1 & 10.7 & 8.0 & & 17.6 & 14.4 & 13.0 & 23.4 & 28.5 \\
\hline & 0.9 & 0.9 & 0.9 & 0.9 & 0.9 & 0.9 & 0.9 & 0.9 & 0.9 & 0.9 & 0.9 & 0.9 & 0.9 & 0.9 & 0.9 & 0.9 & 0.9 & 0.9 & 0.9 & 0.9 & 0.9 & 0.9 & 0.9 & 0.9 & 0.9 & 0.9 & 0.9 & 0.9 & 0.9 & 0.9 & 0.9 & 0.9 & 0.9 & 0.9 & 0.9 & 0.9 & 0.9 & 0.9 \\
\hline 8 & 1.9 & -0.5 & -4.5 & -8.5 & -10. & $\begin{array}{l}-9 . \\
\end{array}$ & -1. & 0.1 & 2.1 & 2.4 & 2.6 & 3.0 & 2.7 & 2.8 & 3.7 & 3.3 & 2.4 & 2.4 & 2.9 & 3.1 & 3.0 & 2.3 & 2.3 & 2.3 & 2.1 & 0.8 & 0.9 & 2.1 & 1.0 & 0.9 & 2.0 & 1.6 & 2.1 & 2.9 & 2.5 & 2.3 & 3.6 & 4.2 \\
\hline 9 & 18.0 & 16.0 & 13.4 & 9.2 & 6.6 & 5.9 & 1.9 & 1.2 & 31.9 & 27.6 & 23.3 & \begin{tabular}{|l|l|}
18.9 \\
\end{tabular} & 4.2 & 1.4 & 4.3 & 0. & -5.1 & -6.6 & -3.2 & -1.2 & -2.3 & -8.3 & -8.8 & -9.0 & 15. & -2.9 & -3.2 & 12.6 & -3.6 & -3.2 & -5.7 & -6.6 & -9.6 & -3.2 & -4.3 & -4.5 & 2.7 & 8.3 \\
\hline 10 & 0.8 & 0.8 & 0.8 & 0.8 & 0.8 & 0.8 & 0.8 & 0.8 & 0.8 & 0.8 & \begin{tabular}{|l|l}
0.8 \\
\end{tabular} & \begin{tabular}{|l|l}
0.8 \\
\end{tabular} & \begin{tabular}{|l|l}
0.8 \\
\end{tabular} & \begin{tabular}{l|l}
0.8 \\
\end{tabular} & 0.8 & 0.8 .8 & 0.8 & 0.8 & 0.8 & \begin{tabular}{l|l}
0.8 \\
\end{tabular} & 0.8 & \begin{tabular}{l|l}
0.8 \\
\end{tabular} & 0.8 & 0.8 & 0.8 & 0.8 & 0.8 & 0.8 & 0.8 & 0.8 & 0.8 & 0.8 & 0.8 & 0.8 & 0.8 & 0.8 & 0.8 & 0.8 \\
\hline 11 & 24.2 & -14.3 & -8.2 & -3.4 & -0.4 & 0.3 & 4.8 & 5.6 & 13.3 & 17.7 & 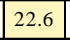 & -29.5 & 11.6 & -8.8 & -12.3 & -7.3 & -0.1 & 0.0 & -3.6 & -5.7 & -4.4 & 2.3 & 2.2 & 2.7 & 7.2 & 5.3 & 5.2 & 5.7 & 5.1 & 5.2 & 2.3 & 4.3 & 3.9 & -3.3 & -0.7 & 0.4 & 10. & -16. \\
\hline 12 & 35.8 & 23.7 & 15.6 & 8.5 & 4.1 & 2.9 & -3.6 & -4.9 & -8.9 & -10.7 & -13.0 & 42.1 & \begin{tabular}{|l|l}
14.3 \\
\end{tabular} & 7.2 & -7.2 & -8.6 & 1.0 & -1.0 & \begin{tabular}{|l|}
-6. \\
\end{tabular} & -8.2 & -7.9 & -5.7 & -3.3 & -2.3 & -6.5 & -5.3 & -5.4 & -6.1 & -5.4 & -5.4 & -6.3 & -5.8 & -6.1 & $\begin{array}{l}-7.7 \\
\end{array}$ & -7.1 & -6.8 & -9.4 & -11.6 \\
\hline 13 & 0.8 & 0.8 & 0.8 & 0.8 & 0.8 & 0.8 & 0.8 & 0.8 & 0.8 & 0.8 & \begin{tabular}{|l|l}
0.8 \\
\end{tabular} & 0.8 & 0.8 & 0.8 & 0.8 & 0.8 & 0.8 & 0.8 & 0.8 & 0.8 & 0.8 & 0.8 & 0.8 & 0.8 & 0.8 & 0.8 & 0.8 & 0.8 & 0.8 & 0.8 & 0.8 & 0.8 & 0.8 & 0.8 & 0.8 & 0.8 & 0.8 & 0.8 \\
\hline 14 & 4.6 & 3.9 & 3.3 & 2.6 & 2.2 & 2.1 & 1.5 & 1.4 & 2.1 & 2.9 & 3.8 & 4.9 & -0.2 & -1.7 & 5.1 & 4.6 & -2.2 & -8.7 & 2.3 & 4.0 & 3.6 & 0.3 & -4.0 & -1.6 & 0.8 & 1.2 & 1.2 & 0.5 & 1.2 & 1.2 & 1.6 & 1.1 & 0.8 & 3.3 & 2.5 & 2.2 & 5.7 & 8.0 \\
\hline 15 & & & 0.9 & 0 & 0 & 0. & 0. & 0. & 0.9 & 0.9 & 0.9 & 0.9 & 0.9 & 0.9 & 0.9 & 0.9 & 0.9 & 0.9 & \begin{tabular}{|l|l|}
$\mid$ \\
$\mid$
\end{tabular} & 0.9 & 0.9 & 0.9 & 0.9 & 0.9 & 0.9 & 9.9 & 0.9 & 0.9 & 0.9 & 0.9 & 0.9 & 0.9 & 0.9 & 0.9 & & & & 0.9 \\
\hline 16 & -7.4 & -6.0 & -4.6 & -3.0 & -2.0 & -1.8 & -0.3 & 0.0 & -2.7 & -4.4 & $\begin{array}{l}-6.1 \\
\end{array}$ & -8.1 & -5.3 & -5.2 & -11.5 & 20.5 & -2.3 & -1.6 & \begin{tabular}{|l|l} 
\\
\end{tabular} & 17.6 & \begin{tabular}{|l|l}
15.6 \\
\end{tabular} & 1.0 & $\begin{array}{c}-0.6 \\
\end{array}$ & -1.3 & -0.3 & 0.5 & 0.6 & 0.5 & 0.7 & 0.6 & 4.9 & 1.7 & 2.0 & 13.8 & 9.7 & 7.9 & -31.5 & -18. \\
\hline 17 & & & & 1. & 1.2 & 1.8 & 1. & 1.1 & 1.4 & 1.9 & 2.4 & 3.0 & 0.3 & -0.4 & 3.1 & 2.8 & -0.6 & -3.3 & \begin{tabular}{|l|l}
1.6 \\
\end{tabular} & 2.5 & 2.3 & 0.6 & -1.4 & -0.3 & 0.8 & 1.0 & 1.0 & 0.6 & 10 & 0 & 1.2 & 0.9 & 0.8 & & 1.7 & & 3.5 & 5.0 \\
\hline 18 & -16.6 & -13.6 & -10.7 & $\begin{array}{l}-7.5 \\
\end{array}$ & -5.5 & -5.0 & -1.9 & -1.3 & -4.7 & -8.9 & $\mid-13.1$ & -18.1 & \begin{tabular}{|l|l}
6.8 \\
\end{tabular} & 15.5 & -19.3 & -16.8 & \begin{tabular}{|l|l|}
18.2 \\
\end{tabular} & \begin{tabular}{|lll}
87.7 \\
\end{tabular} & \begin{tabular}{|l|l|} 
\\
\end{tabular} & -14.1. & -12.2 & \begin{tabular}{|l|l}
4.2 \\
\end{tabular} & 29.9 & \begin{tabular}{|l|l}
14.7 \\
\end{tabular} & 1.8 & -0.5 & -0.4 & 3.3 & -0.3 & -0.4 & \begin{tabular}{|c|}
-2.6 \\
\end{tabular} & 0.4 & 1.6 & & -6.8 & -5.2 & -21.8 & -32.2 \\
\hline & 0.8 & 0.8 & 0.8 & 0.8 & 0.8 & 0.8 & 0.8 & 0.8 & 0.8 & 0.8 & 0.8 & 0.8 & 0.8 & 0.8 & 0.8 & 0.8 & 0.8 & 0.8 & 0.8 & 0.8 & 0.8 & 0.8 & 0.8 & 0.8 & 0.8 & 0.8 & 0.8 & \begin{tabular}{|l|l|}
0.8 \\
\end{tabular} & 0.8 & 0.8 & 0.8 & 0.8 & 0.8 & 0.8 & 0.8 & 0.8 & 0.8 & 0.8 \\
\hline 20 & 6.1 & 4.6 & 3.2 & 1.6 & 0.6 & 0.3 & -1.2 & -1.4 & 1.3 & 3.0 & 4.8 & \begin{tabular}{|l|l}
6.8 \\
\end{tabular} & 4.4 & \begin{tabular}{|l|l}
4.6 \\
\end{tabular} & \begin{tabular}{|l|l}
12.9 \\
\end{tabular} & \begin{tabular}{|l|l}
32.8 \\
\end{tabular} & \begin{tabular}{|l|l}
1.2 \\
\end{tabular} & \begin{tabular}{|l|l|}
0.6 \\
\end{tabular} & \begin{tabular}{|l|l}
6.2 \\
\end{tabular} & 35.6 & -20.0 & \begin{tabular}{|l|l|} 
\\
\end{tabular} & \begin{tabular}{|l|} 
\\
\end{tabular} & 0.1 & -1.0 & -2.0 & -2.1 & \begin{tabular}{|l|}
-1.9 \\
\end{tabular} & 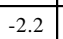 & $\mid-2.1$ & $\mid$\begin{tabular}{|c|}
-7.1 \\
\end{tabular} & -3.2 & -3.5 & & & & & 16.8 \\
\hline & -4.4 & -2.9 & -1.5 & 0 & 1.1 & 1.3 & 2.8 & 3.1 & 0.3 & \begin{tabular}{|c|}
-1.4 \\
\end{tabular} & $\mid-3.1$ & \begin{tabular}{|l|l} 
& \\
\end{tabular} & $\mid-2.8$ & \begin{tabular}{|l|l|} 
\\
\end{tabular} & -11.2 & -31.1 & \begin{tabular}{|l|l}
0.4 \\
\end{tabular} & 1.0 & \begin{tabular}{|l|l|}
-4.6 \\
\end{tabular} & -33.9 & 21.6 & \begin{tabular}{|l|l|}
3.2 \\
\end{tabular} & \begin{tabular}{|l|}
2.1 \\
\end{tabular} & 1.5 & 2.7 & 3.6 & 3.7 & 3.6 & 3.9 & \begin{tabular}{|l|}
3.8 \\
\end{tabular} & \begin{tabular}{|l|l|}
8.7 \\
\end{tabular} & 4.8 & 5.1 & 19.5 & 14.5 & 12.3 & -26.0 & -15.1 \\
\hline 22 & 0.8 & \begin{tabular}{|l|}
0.8 \\
\end{tabular} & \begin{tabular}{|l}
0.8 \\
\end{tabular} & 0.8 & 0.8 & 0.8 & 0.8 & 0.8 & 0.8 & 0.8 & \begin{tabular}{|l|l|}
0.8 \\
\end{tabular} & \begin{tabular}{|l|l}
0.8 \\
\end{tabular} & \begin{tabular}{|l}
0.8 \\
\end{tabular} & \begin{tabular}{|l}
0.8 \\
\end{tabular} & \begin{tabular}{|l|l}
0.8 \\
\end{tabular} & \begin{tabular}{|l}
0.8 \\
\end{tabular} & \begin{tabular}{|l}
0.8 \\
\end{tabular} & \begin{tabular}{|l}
0.8 \\
\end{tabular} & \begin{tabular}{|l|l}
0.8 \\
\end{tabular} & \begin{tabular}{|l|l}
0.8 \\
\end{tabular} & \begin{tabular}{|l|}
0.8 \\
\end{tabular} & \begin{tabular}{|l|l}
0.8 \\
\end{tabular} & \begin{tabular}{|l|l}
0.8 \\
\end{tabular} & 0.8 & 0.8 & 0.8 & 0.8 & 0.8 & 0.8 & 0.8 & 0.8 & 0.8 & 0.8 & 0.8 & 0.8 & 0.8 & 0.8 & 0.8 \\
\hline & 1 & 10 & 9 & 6.8 & 5 & 5 & 2 & & 4 & 7.8 & 10.6 & \begin{tabular}{|l|l}
13.9 \\
\end{tabular} & \begin{tabular}{|l|l|} 
\\
\end{tabular} & \begin{tabular}{|l|l}
-9.7 \\
\end{tabular} & \begin{tabular}{|l|l}
14.7 \\
\end{tabular} & \begin{tabular}{|l|l}
13.1 \\
\end{tabular} & -11.7 & $\mid-72.1$ & \begin{tabular}{|l|l}
5.8 \\
\end{tabular} & \begin{tabular}{|l|l}
11.3 \\
\end{tabular} & 10.0 & \begin{tabular}{|l|l|} 
\\
\end{tabular} & -20.8 & \begin{tabular}{|l|l}
-9.1 \\
\end{tabular} & 0.3 & 1.9 & \begin{tabular}{|l}
1.9 \\
\end{tabular} & \begin{tabular}{|c|}
-0.7 \\
\end{tabular} & \begin{tabular}{ll|}
1.8 \\
\end{tabular} & \begin{tabular}{|l|}
1.9 \\
\end{tabular} & \begin{tabular}{|l|}
3.4 \\
\end{tabular} & \begin{tabular}{|l|l|}
1.3 \\
\end{tabular} & 0.5 & 8.8 & 6.4 & 5.3 & & 22.9 \\
\hline 24 & 1.0 & \begin{tabular}{|l|}
1.0 \\
\end{tabular} & 1.0 & 1.0 & 1.0 & 1.0 & 1.0 & 1.0 & 1.0 & 1.0 & \begin{tabular}{|l|l|}
1.0 \\
\end{tabular} & \begin{tabular}{|l|l}
1.0 \\
\end{tabular} & \begin{tabular}{|l|l}
1.0 \\
\end{tabular} & \begin{tabular}{|l|l}
1.0 \\
\end{tabular} & \begin{tabular}{|l|l}
1.0 \\
\end{tabular} & \begin{tabular}{|l|l}
1.0 \\
\end{tabular} & \begin{tabular}{|l|l}
1.0 \\
\end{tabular} & \begin{tabular}{|l|l}
1.0 \\
\end{tabular} & \begin{tabular}{|l|l}
1.0 \\
\end{tabular} & \begin{tabular}{|l|l}
1.0 \\
\end{tabular} & \begin{tabular}{|l|l}
1.0 \\
\end{tabular} & \begin{tabular}{|l|l}
1.0 \\
\end{tabular} & \begin{tabular}{|l|}
1.0 \\
\end{tabular} & 1.0 & 1.0 & 1.0 & 1.0 & \begin{tabular}{ll|}
1.0 \\
\end{tabular} & 1.0 & 1.0 & \begin{tabular}{|l}
1.0 \\
\end{tabular} & \begin{tabular}{ll|}
1.0 \\
\end{tabular} & 1.0 & 1.0 & 1.0 & 1.0 & 1.0 & 1.0 \\
\hline & 6.5 & -1 & -1 & \begin{tabular}{|l|l} 
\\
\end{tabular} & -5.0 & -4.3 & -0.4 & 0.4 & -30.4 & 6.1 & $\mid-21.8$ & -17.4 & \begin{tabular}{|l|}
-2.6 \\
\end{tabular} & \begin{tabular}{|l|l}
0.2 \\
\end{tabular} & $\mid-2.7$ & \begin{tabular}{|l|l}
1.4 \\
\end{tabular} & \begin{tabular}{|l|l}
6.6 \\
\end{tabular} & 8.2 & \begin{tabular}{|l|l}
4.7 \\
\end{tabular} & \begin{tabular}{|l|l}
2.8 \\
\end{tabular} & \begin{tabular}{|l|l}
3.8 \\
\end{tabular} & \begin{tabular}{|l|}
9.9 \\
\end{tabular} & 10.3 & 10.6 & 16.6 & 4.4 & $4.7 \mid$ & 14.2 & 5.2 & 4.8 & \begin{tabular}{|l|}
7.2 \\
\end{tabular} & \begin{tabular}{|l|l|}
8.2 \\
\end{tabular} & 11.1 & 4.7 & 5.9 & 6.4 & -1.2 & $\begin{array}{l}-6.7 \\
\end{array}$ \\
\hline 26 & 2.6 & \begin{tabular}{|l}
2.3 \\
\end{tabular} & 2.1 & \begin{tabular}{|l|l}
1.7 \\
\end{tabular} & 1.5 & 1.5 & 1.2 & 1.1 & 2.1 & 2.3 & \begin{tabular}{|l|}
2.5 \\
\end{tabular} & \begin{tabular}{|l|l}
2.7 \\
\end{tabular} & 2.4 & 2.4 & \begin{tabular}{|l}
2.9 \\
\end{tabular} & \begin{tabular}{|l}
2.6 \\
\end{tabular} & 2.1 .1 & \begin{tabular}{|l|l}
2.1 \\
\end{tabular} & 2.3 & \begin{tabular}{|l}
2.5 \\
\end{tabular} & 2.4 & \begin{tabular}{|l|l}
1.9 \\
\end{tabular} & \begin{tabular}{|l|l}
2.0 \\
\end{tabular} & 2.0 & 1.9 & 1.0 & \begin{tabular}{|l|l|}
-149 \\
\end{tabular} & \begin{tabular}{|l|}
1.9 \\
\end{tabular} & 1.0 & & \begin{tabular}{|l|l|}
1.7 \\
\end{tabular} & \begin{tabular}{|l|}
1.4 \\
\end{tabular} & $\begin{array}{ll}1.8 \\
\end{array}$ & 2.3 & 2.0 & 1.9 & 2.8 & 3.3 \\
\hline & -0.8 & -0.5 & -0.2 & 0.1 & 0.3 & 0 & 0 & & \begin{tabular}{c|}
-0.2 \\
\end{tabular} & \begin{tabular}{c|c|}
-0.4 \\
\end{tabular} & \begin{tabular}{|l|l|l|l|}
-1 & \\
\end{tabular} & \begin{tabular}{|l|}
-0.9 \\
\end{tabular} & \begin{tabular}{|l|l|}
-0.6 \\
\end{tabular} & \begin{tabular}{|l|l|} 
\\
\end{tabular} & \begin{tabular}{|l|l}
-1.1 \\
\end{tabular} & \begin{tabular}{|l|l|}
-0.8 \\
\end{tabular} & \begin{tabular}{|l|l|}
-0.3 \\
\end{tabular} & \begin{tabular}{|l|l|}
-0.2 \\
\end{tabular} & \begin{tabular}{|l|l|} 
\\
\end{tabular} & \begin{tabular}{|l|l|} 
& \\
\end{tabular} & \begin{tabular}{|l|l|}
-0.6 \\
\end{tabular} & \begin{tabular}{|l|l|} 
& \\
\end{tabular} & \begin{tabular}{|l|l|} 
\\
\end{tabular} & $\begin{array}{c}-0.2 \\
\end{array}$ & -0.1 & 0.9 & \begin{tabular}{|l|}
30.7 \\
\end{tabular} & 0.0 & 0.8 & 0.7 & \begin{tabular}{|l|l|}
0.1 \\
\end{tabular} & \begin{tabular}{|l|}
0.4 \\
\end{tabular} & \begin{tabular}{|c|}
0.0 \\
\end{tabular} & -0.5 & -0.2 & -0.1 & -1.0 & -1.5 \\
\hline 28 & 0.9 & 0.9 & 0.9 & 0.9 & \begin{tabular}{|l|l}
0.9 \\
\end{tabular} & \begin{tabular}{|l|l}
0.9 \\
\end{tabular} & 0.9 & 0.9 & \begin{tabular}{ll|}
0.9 \\
\end{tabular} & 0.9 & \begin{tabular}{|l|}
0.9 \\
\end{tabular} & \begin{tabular}{|l|l}
0.9 \\
\end{tabular} & \begin{tabular}{|l|l}
0.9 \\
\end{tabular} & \begin{tabular}{|l}
0.9 \\
\end{tabular} & \begin{tabular}{|l}
0.9 \\
\end{tabular} & \begin{tabular}{|l|l}
0.9 \\
\end{tabular} & \begin{tabular}{|l|l}
0.9 \\
\end{tabular} & \begin{tabular}{|l}
0.9 \\
\end{tabular} & \begin{tabular}{|l|l}
0.9 \\
\end{tabular} & \begin{tabular}{|l|l}
0.9 \\
\end{tabular} & \begin{tabular}{|l|l}
0.9 \\
\end{tabular} & \begin{tabular}{|l|l}
0.9 \\
\end{tabular} & \begin{tabular}{|l|l}
0.9 \\
\end{tabular} & \begin{tabular}{|c|}
0.9 \\
\end{tabular} & 0.9 & 0.9 & \begin{tabular}{|l|}
0.9 \\
\end{tabular} & \begin{tabular}{|l|}
0.9 \\
\end{tabular} & 0.9 & \begin{tabular}{|l|}
0.9 \\
\end{tabular} & \begin{tabular}{|l|l|} 
\\
\end{tabular} & 0.9 & 0.9 & 0.9 & 0.9 & 0.9 & 0.9 & 0.9 \\
\hline 26 & 2.7 & 2.4 & 2.2 & 1.8 & 1. & \begin{tabular}{|l}
1.6 \\
\end{tabular} & 1. & 1.2 & 2.2 & 2.4 & 2.6 & \begin{tabular}{|l|l|}
2.8 \\
\end{tabular} & \begin{tabular}{|l|l}
2.5 \\
\end{tabular} & \begin{tabular}{|l|l}
2.5 \\
\end{tabular} & \begin{tabular}{|l|l}
3.0 \\
\end{tabular} & 2.7 & 2.2 & 2.2 & 2.4 & \begin{tabular}{|l|l}
2.6 \\
\end{tabular} & \begin{tabular}{|l|l}
2.5 \\
\end{tabular} & 2.0 & \begin{tabular}{|l|l}
2.1 \\
\end{tabular} & 2.1 & 2.0 & 1.1 & -12.8 & 2.0 & 1.1 & \begin{tabular}{|l|l|l|}
-14.7 \\
\end{tabular} & 1.8 & 1.5 & 1.9 & 2.4 & 2.1 & 2.0 & 2.9 & 3.4 \\
\hline 30 & -0.7 & -0.5 & -0.2 & 0.1 & 0.3 & 0.3 & 0.6 & 0.7 & -0.2 & -0.4 & \begin{tabular}{l|l|l|l|}
-0 \\
\end{tabular} & \begin{tabular}{|l|l|} 
\\
\end{tabular} & \begin{tabular}{|l|l|}
-0.6 \\
\end{tabular} & $\mid-0.6$ & \begin{tabular}{|l|l|}
-1.1 \\
\end{tabular} & \begin{tabular}{|l|l|}
-0.7 \\
\end{tabular} & \begin{tabular}{|l|l|} 
\\
\end{tabular} & \begin{tabular}{|l|l|}
-0.2 \\
\end{tabular} & \begin{tabular}{|l|l|} 
\\
\end{tabular} & \begin{tabular}{|l|l|}
-0.6 \\
\end{tabular} & $\mid-0.5$ & \begin{tabular}{|l|l|} 
& -1 \\
\end{tabular} & \begin{tabular}{|l|l|} 
& -1 \\
\end{tabular} & \begin{tabular}{|c|}
-0.2 \\
\end{tabular} & 0.0 & 0.8 & \begin{tabular}{|l|}
0.7 \\
\end{tabular} & 0.0 & \begin{tabular}{|l|}
0.9 \\
\end{tabular} & \begin{tabular}{|l|}
30.7 \\
\end{tabular} & \begin{tabular}{|l|}
0.2 \\
\end{tabular} & \begin{tabular}{|l|l|}
0.4 \\
\end{tabular} & 0.0 & -0.5 & -0.1 & 0.0 & -1.0 & -1.4 \\
\hline & 8.0 & 6.8 & 5.7 & 4.5 & 3.7 & 3.5 & 2.3 & 2.1 & 4.8 & 5.9 & 7.1 & 8.6 & \begin{tabular}{|l|l|}
6.3 \\
\end{tabular} & 6.1 & 8.7 & 3.9 & 4.5 & 4.1 & 4.9 & 2.7 & 1.8 & 2.8 & \begin{tabular}{|l|l}
3.5 \\
\end{tabular} & 3.9 & 3.3 & 1.7 & 1.5 & 2.9 & 1.4 & 1.5 & -14.2 & 0.4 & 2.1 & 1.0 & 18.3 & -25.6 & 6.1 & 11.3 \\
\hline 32 & 0.7 & 0.7 & 0.7 & 0.7 & 0.7 & 0. & 0.7 & 0.7 & 0.7 & 0.7 & \begin{tabular}{|l|l}
0.7 \\
\end{tabular} & \begin{tabular}{|l|l|}
0.7 \\
\end{tabular} & $\begin{array}{ll}0.7 \\
\end{array}$ & \begin{tabular}{|l|l}
0.7 \\
\end{tabular} & \begin{tabular}{|l|l}
0.7 \\
\end{tabular} & 0.7 & \begin{tabular}{|l|l|}
0.7 \\
\end{tabular} & \begin{tabular}{|l|l|}
0.7 \\
\end{tabular} & \begin{tabular}{|l|l}
0.7 \\
\end{tabular} & \begin{tabular}{|l|l}
0.7 \\
\end{tabular} & 0.7 & $\begin{array}{ll}0.7 \\
\end{array}$ & 0.7 & 0.7 & 0.7 & 0.7 & 0.7 & 0.7 & 0.7 & 0.7 & 0.7 & 0.7 & 0.7 & 0.7 & 0.7 & 0.7 & 0.7 & 0.7 \\
\hline & 1 & 1. & 1. & 1. & \begin{tabular}{|l|l}
1.1 \\
\end{tabular} & 1.1 & 1.1 & 1.1 & 1.1 & 1.1 & 1.1 .1 & 1.1 .1 & 1.1 .1 & $\begin{array}{ll}1.1 \\
\end{array}$ & 1.1 & 1.1 & 1.1 & 1.1 & \begin{tabular}{|l|l}
1.1 \\
\end{tabular} & 1.1 .1 & 1.1 & 1.1 & 1.1 & 1.1 & 1.1 & 1.1 & 1.1 & 1.1 & 1.1 & 1.1 & 1.1 & 1.1 & 1.1 & 1.1 & 1.1 & 1.1 & 1.1 & 1.1 \\
\hline 34 & 0.9 & 0.9 & 0.9 & 0.9 & 0.9 & 0.9 & 0. & 0. & 0.9 & 0.9 & \begin{tabular}{|l|l}
0.9 \\
\end{tabular} & \begin{tabular}{l|l}
0.9 \\
\end{tabular} & 0.9 & 0.9 & 0.9 & 0.9 & 0.9 & 0.9 & 0.9 & 0.9 & 0.9 & 0.9 & 0.9 & 0.9 & 0.9 & 0.9 & 0.9 & 0.9 & 0.9 & 0.9 & 0.9 & 0.9 & 0.9 & 0.9 & 0.9 & & 0.9 & 0.9 \\
\hline 3. & 11 & 9.5 & 8.0 & 6.1 & 5.0 & 4.7 & 3.0 & 2.7 & 6.6 & 8.2 & 100 & \begin{tabular}{|l|l}
12.0 \\
\end{tabular} & \begin{tabular}{|l|l}
8.8 \\
\end{tabular} & 8.4 & 12.2 & \begin{tabular}{|l|l}
5.3 \\
\end{tabular} & 6.2 & 5.6 & 6.8 & 3.6 & 2.2 & 3.7 & 4.8 & 5.3 & 4.5 & 2.0 & 1.8 & 3.8 & 1.6 & 1.8 & $\begin{array}{l}23.4 \\
\end{array}$ & 0.1 & 2.7 & 1.0 & 30.3 & -43.1 & 8.5 & 15.7 \\
\hline 36 & 165 & -13.7 & & $\begin{array}{c}-7.9 \\
\end{array}$ & $\begin{array}{l}-6.0 \\
\end{array}$ & -5.5 & -2 & & 8.8 & & & & & & & -65 & -8. & 1.70 & |-9.0 & 23 & & -38 & & & & & & & 03 & 06 & 40.3 & 22 & & & 51.3 & & & \\
\hline 37 & 9.1 & 7.7 & 6.3 & 4.7 & 3.7 & 3.5 & 2.0 & 1.7 & 4.4 & 6.1 & 7.8 & 9.8 & 7.0 & 6.9 & 13.3 & |-18.8 & 4.0 & 3.3 & 4.3 & 15.9 & -13.8 & 0.7 & 2.3 & 3.0 & 2.0 & 1.2 & 1.1 & 1.2 & 1.0 & 1.1 & -3.2 & 0.0 & -0.3 & -12.1 & -8.0 & -6.2 & 33.2 & 20.0 \\
\hline 38 & 0.4 & 0.4 & 0.4 & 0.4 & 0.4 & 0.4 & 0.4 & 0.4 & 0.4 & 0.4 & 0.4 & 0.4 & 0.4 & 0.4 & 0.4 & 0.4 & 0.4 & 0.4 & 0.4 & 0.4 & 0.4 & 0.4 & & & & 0.7 & & 0.4 & 0.4 & 0.4 & 0.4 & 0.4 & 0.4 & 0.4 & 0.4 & 0.4 & & 0.4 \\
\hline
\end{tabular}


Table D3. Leak flows obtained with 5 pressure sensors and 5 flowmeters, installed at the least sensitive elements of the network (nodes 1, 12, 15, $16,38$ and pipes $6,16,43,46,56)$

\begin{tabular}{|l|l|l|l|l|l|l|l|l|l|l|l|l|l|l|l|l|l|l|l|l|l|l|l|l|l|l|l|l|l|l|l|l|l|l|l|l|l|l|l|l|l|l|l|l|l|l|}
\hline 1 & 2 & 3 & 4 & 5 & 6 & 7 & 8 & 9 & 10 & 11 & 12 & 13 & 14 & 15 & 16 & 17 & 18 & 19 & 20 & 21 & 22 & 23 & 24 & 25 & 26 & 27 & 28 & 29 & 30 & 31 & 32 & 33 & 34 & 35 & 36 & 37 & 38 \\
\hline
\end{tabular}

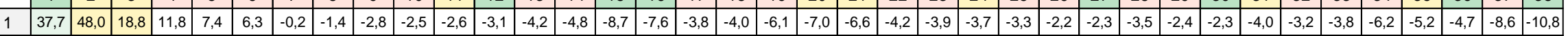

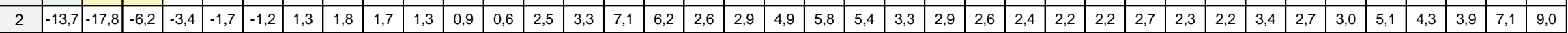

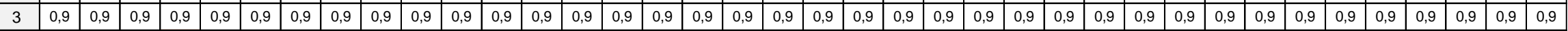

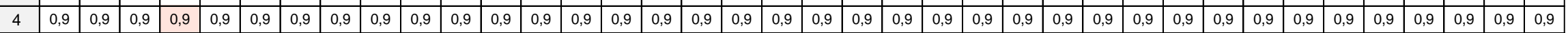

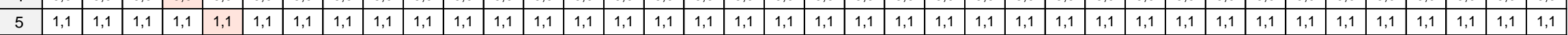

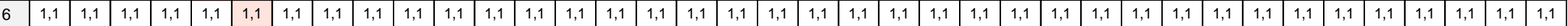

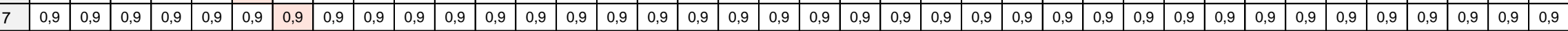

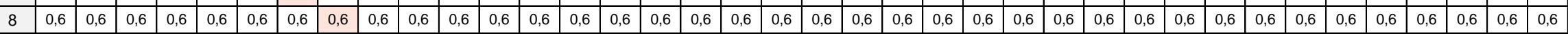
\begin{tabular}{|lllllllllllllllllllllllllllllllllllllllllllllllll}
9 & 0,8 & 0,8 & 0,8 & 0,8 & 0,8 & 0,8 & 0,8 & 0,8 & 0,8 & 0,8 & 0,8 & 0,8 & 0,8 & 0,8 & 0,8 & 0,8 & 0,8 & 0,8 & 0,8 & 0,8 & 0,8 & 0,8 & 0,8 & 0,8 & 0,8 & 0,8 & 0,8 & 0,8 & 0,8 & 0,8 & 0,8 & 0,8 & 0,8 & 0,8 & 0,8 & 0,8 & 0,8 & 0,8 \\
\hline
\end{tabular}

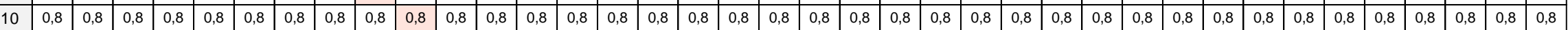

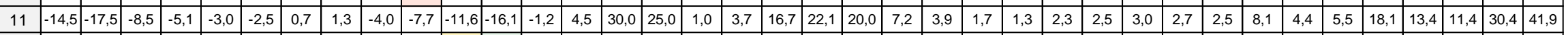

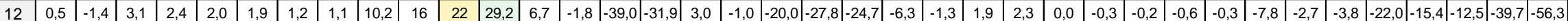
\begin{tabular}{|l|l|l|l|l|l|l|l|l|l|l|l|l|l|l|l|l|l|l|l|lllllllllllllllllllllllll}
13 & $-0,8$ & $-1,1$ & $-0,1$ & 0,2 & 0,4 & 0,5 & 0,8 & 0,9 & 0,3 & $-0,1$ & $-0,5$ & $-0,9$ & 0,6 & 1,2 & 3,9 & 3,4 & 0,9 & 1,1 & 2,5 & 3,1 & 2,9 & 1,5 & 1,2 & 0,9 & 0,9 & 1,0 & 1,0 & 1,1 & 1,0 & 1,0 & 1,6 & 1,2 & 1,3 & 2,7 & 2,2 & 2,0 & 4,0 & 5,2 \\
\hline
\end{tabular}

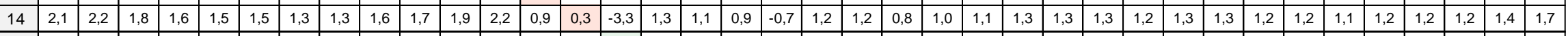

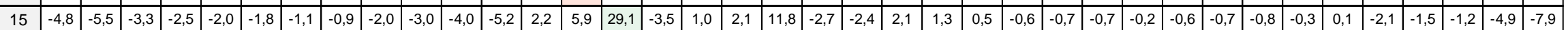

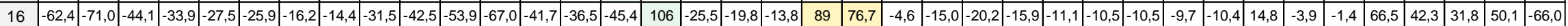

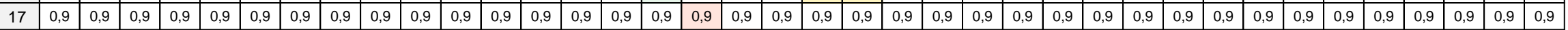

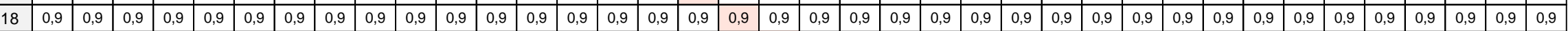

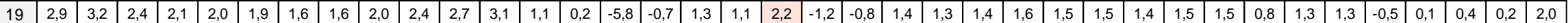

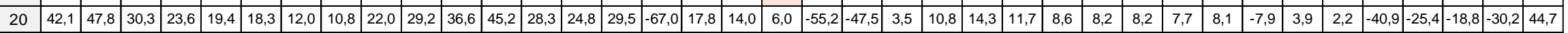

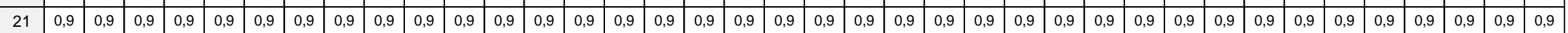

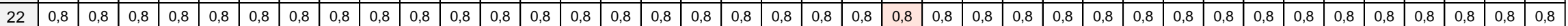
\begin{tabular}{|l|l|l|l|l|l|l|l|l|l|l|l|l|l|l|l|l|l|l|l|l|l|l|l|l|l|l|l|lllllllllll}
23 & 0,6 & 0,7 & 0,8 & 0,9 & 1,0 & 1,0 & 1,1 & 1,1 & 0,5 & 0,5 & 0,5 & 0,5 & $-0,5$ & 1,5 & 1,5 & 1,5 & $-12,0$ & 5,2 & 2,2 & 1,5 & 1,6 & 2,8 & 7,0 & $-12,6$ & 0,5 & 1,2 & 1,2 & 1,5 & 1,3 & 1,2 & 1,5 & 1,5 & 1,8 & 1,6 & 1,6 & 1,6 & 1,4 & 1,1 \\
\hline
\end{tabular}

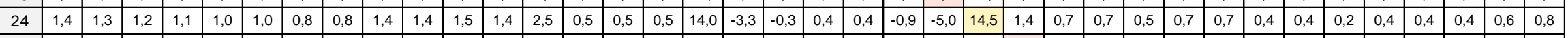
\begin{tabular}{|l|l|l|l|l|l|l|l|l|l|l|llllllllllllllllllllllllllllllllllll}
\hline 25 & 0,8 & 0,8 & 0,8 & 0,8 & 0,8 & 0,8 & 0,8 & 0,8 & 0,8 & 0,8 & 0,8 & 0,8 & 0,8 & 0,8 & 0,8 & 0,8 & 0,8 & 0,8 & 0,8 & 0,8 & 0,8 & 0,8 & 0,8 & 0,8 & 0,8 & 0,8 & 0,8 & 0,8 & 0,8 & 0,8 & 0,8 & 0,8 & 0,8 & 0,8 & 0,8 & 0,8 & 0,8 & 0,8 \\
\hline
\end{tabular}

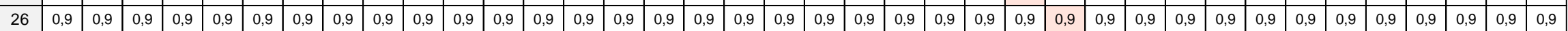
\begin{tabular}{|l|l|l|l|l|l|l|l|l|l|l|l|l|l|l|l|l|l|l|l|l|l|l|l|l|l|l|l|l|l|l|l|l|llllll}
\hline 27 & 0,9 & 0,9 & 1,0 & 1,0 & 1,0 & 1,0 & 1,0 & 1,0 & 0,9 & 0,9 & 0,9 & 0,9 & 0,9 & 0,9 & 0,9 & 0,9 & 0,9 & 0,9 & 0,9 & 0,9 & 0,9 & 0,9 & 0,9 & 0,9 & 0,9 & 1,0 & 21,6 & 0,9 & 0,8 & $-20,5$ & 0,9 & 0,9 & 0,9 & 0,9 & 0,9 & 0,9 & 0,9 & 0,9 \\
\hline
\end{tabular} \begin{tabular}{lllllllllllllllllllllllllllllllllllllllllllllllllllllll}
28 & 0,9 & 0,9 & 0,9 & 0,9 & 0,9 & 0,9 & 0,9 & 0,9 & 0,9 & 0,9 & 0,9 & 0,9 & 0,9 & 0,9 & 0,9 & 0,9 & 0,9 & 0,9 & 0,9 & 0,9 & 0,9 & 0,9 & 0,9 & 0,9 & 0,9 & 0,9 & 0,9 & 0,9 & 0,9 & 0,9 & 0,9 & 0,9 & 0,9 & 0,9 & 0,9 & 0,9 & 0,9 & 0,9 \\
\hline
\end{tabular}

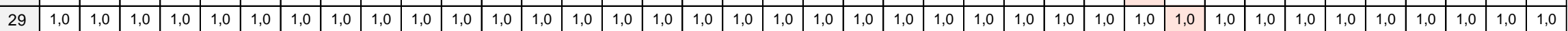

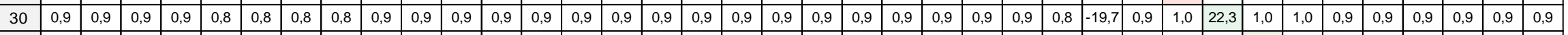

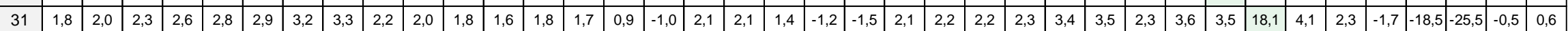

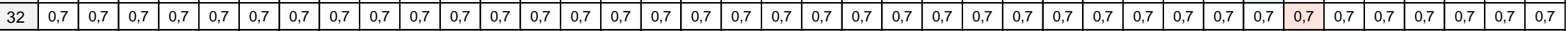

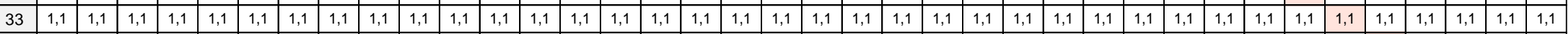

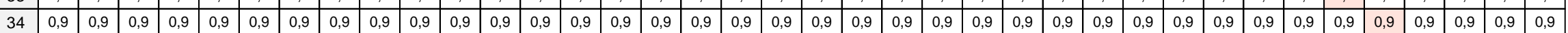

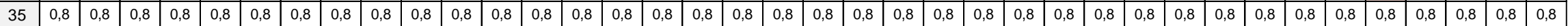

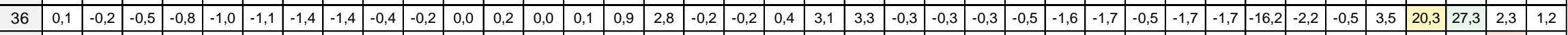

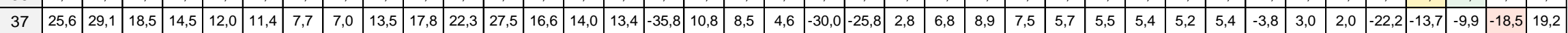

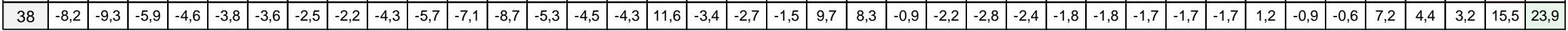


Table D4. Leak flows obtained with 5 pressure sensors and 5 flowmeters, installed according to spatial distribution criteria (nodes 2, 8, 18, 20, 32 and pipes $11,17,25,36,42)$

\begin{tabular}{|l|l|l|l|l|l|l|l|l|l|l|l|l|l|l|l|l|l|l|l|l|l|l|l|l|l|l|l|l|l|l|l|l|l|l|l|l|l|}
\hline 1 & 2 & 3 & 4 & 5 & 6 & 7 & 8 & 9 & 10 & 11 & 12 & 13 & 14 & 15 & 16 & 17 & 18 & 19 & 20 & 21 & 22 & 23 & 24 & 25 & 26 & 27 & 28 & 29 & 30 & 31 & 32 & 33 & 34 & 35 & 36 & 37 & 38 \\
\hline
\end{tabular}

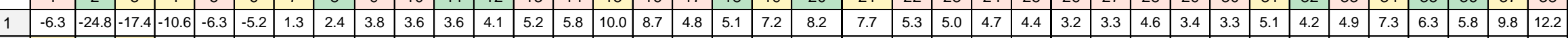

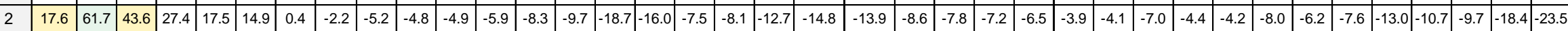

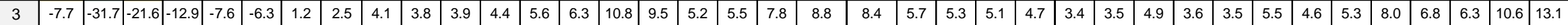

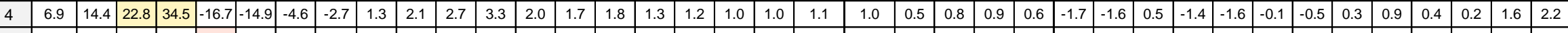

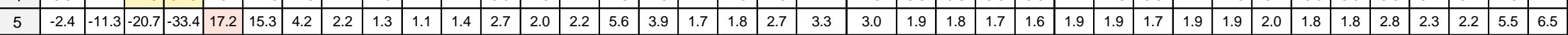

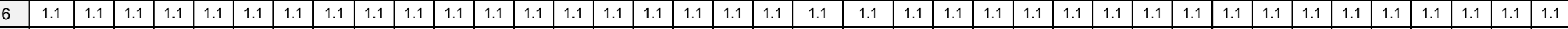

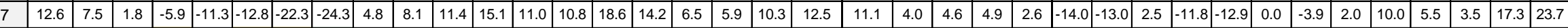

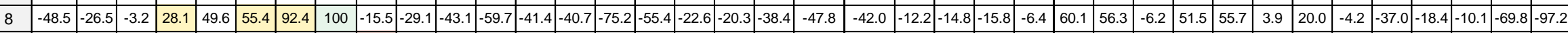

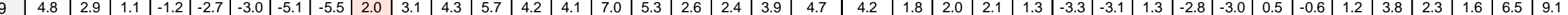

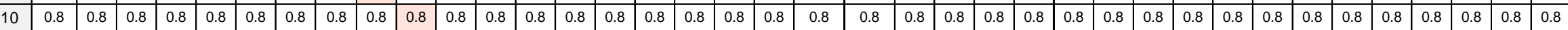

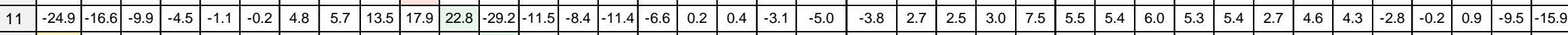

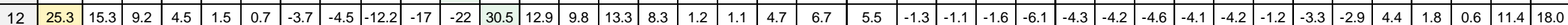
\begin{tabular}{lllllllllllllllllllllllllllllllllllllllllllllllll}
13 & 0.8 & 0.8 & 0.8 & 0.8 & 0.8 & 0.8 & 0.8 & 0.8 & 0.8 & 0.8 & 0.8 & 0.8 & 0.8 & 0.8 & 0.8 & 0.8 & 0.8 & 0.8 & 0.8 & 0.8 & 0.8 & 0.8 & 0.8 & 0.8 & 0.8 & 0.8 & 0.8 & 0.8 & 0.8 & 0.8 & 0.8 & 0.8 & 0.8 & 0.8 & 0.8 & 0.8 & 0.8 & 0.8 \\
\hline
\end{tabular}

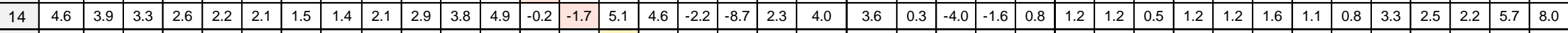

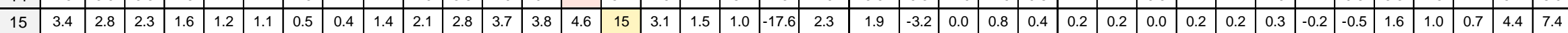

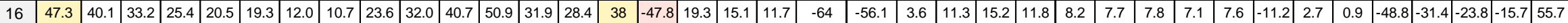

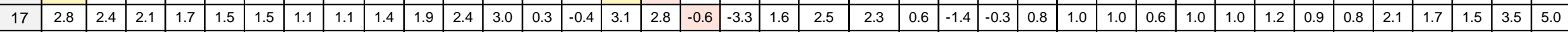

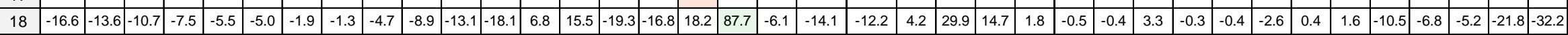

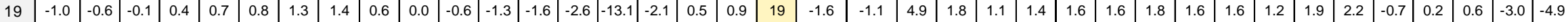

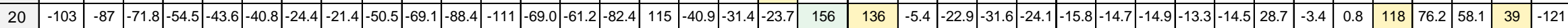

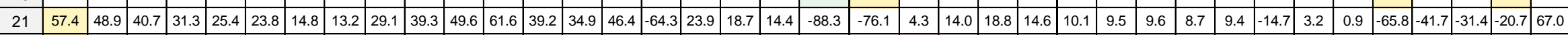

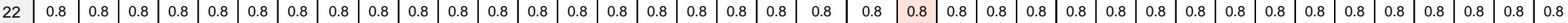

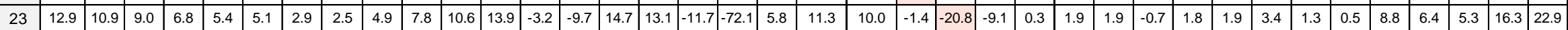

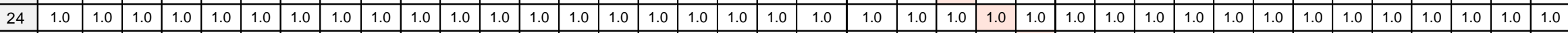

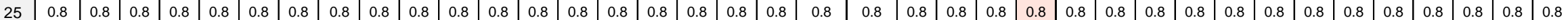

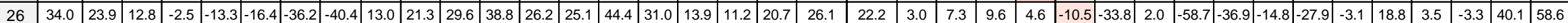

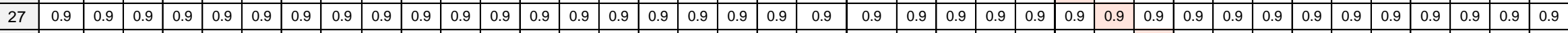

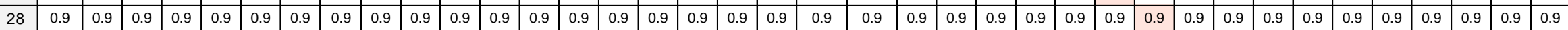

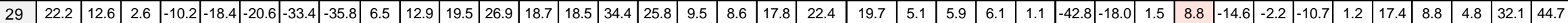
\begin{tabular}{|l|l|l|l|l|l|l|l|l|l|l|l|l|l|l|l|l|l|l|l|l|l|l|l|l|l|l|l|l|l|l|l|l|l|l|l|l|l|l}
\hline 30 & 0.9 & 0.9 & 0.9 & 0.9 & 0.9 & 0.9 & 0.9 & 0.9 & 0.9 & 0.9 & 0.9 & 0.9 & 0.9 & 0.9 & 0.9 & 0.9 & 0.9 & 0.9 & 0.9 & 0.9 & 0.9 & 0.9 & 0.9 & 0.9 & 0.9 & 0.9 & 0.9 & 0.9 & 0.9 & 0.9 & 0.9 & 0.9 & 0.9 & 0.9 & 0.9 & 0.9 & 0.9 & 0.9 \\
\hline
\end{tabular}

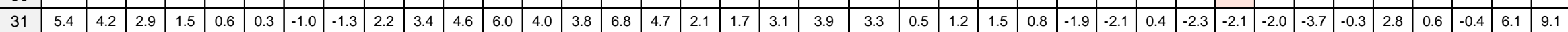

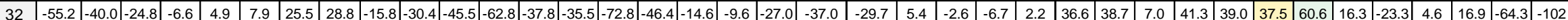

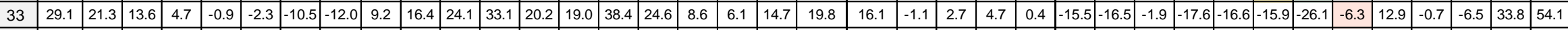

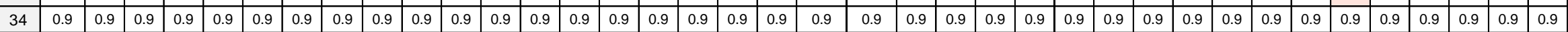

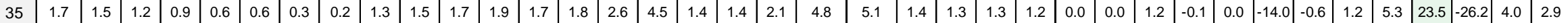

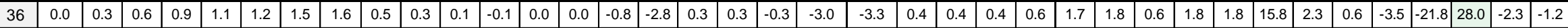

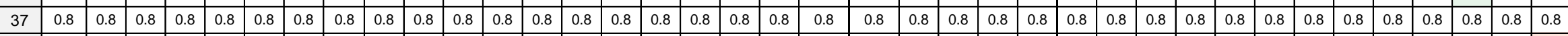
\begin{tabular}{|l|l|l|l|l|l|l|l|l|l|l|l|l|l|l|l|l|l|l|l|l|l|l|l|l|l|l|l|l|l|l|l|l|l|l|l|l|l|l|}
\hline 38 & 0.4 & 0.4 & 0.4 & 0.4 & 0.4 & 0.4 & 0.4 & 0.4 & 0.4 & 0.4 & 0.4 & 0.4 & 0.4 & 0.4 & 0.4 & 0.4 & 0.4 & 0.4 & 0.4 & 0.4 & 0.4 & 0.4 & 0.4 & 0.4 & 0.4 & 0.4 & 0.4 & 0.4 & 0.4 & 0.4 & 0.4 & 0.4 & 0.4 & 0.4 & 0.4 & 0.4 & 0.4 & 0.4 \\
\hline
\end{tabular} 
Table D5. Leak flows obtained with 10 pressure sensors (nodes 2, 5, 8, 18, 19, 20, 27, 30, 32, 36)

\begin{tabular}{|c|c|c|c|c|c|c|c|c|c|c|c|c|c|c|c|c|c|c|c|c|c|c|c|c|c|c|c|c|c|c|c|c|c|c|c|c|c|c|}
\hline & & & & & & & & & & & & & & & & & & & & & & & & & & & & & & & & & & & & & & \\
\hline & -6 & & & & & -5.2 & 1. & & & & & & & 5.8 & 10.0 & 8.7 & 1.8 & & & & & 5.3 & 5.0 & 4.7 & 4.4 & 3.2 & 3.3 & 4.6 & 3.4 & & & 4.2 & 4.9 & 7.3 & 6.3 & 5.8 & & \\
\hline & 6 & & & 27.4 & & 14.9 & & & & & & & & & 8. & -16.0 & 7.5 & & 2.7 & 14.8 & 3.9 & \begin{tabular}{|l|}
-8.6 \\
\end{tabular} & \begin{tabular}{|l|l|}
-7.8 \\
\end{tabular} & $-7.2 \mid$ & 6.5 & 3.9 & -4.1 & & \begin{tabular}{|l|}
-4.4 \\
\end{tabular} & -4.2 & \begin{tabular}{|c|c|}
-8.0 & -6
\end{tabular} & -6.2 & 7.6 & -13. & 10. & -9.7 & 18 & \\
\hline & & & & & & & & & & & & & & & & & & & & & & & & & & & & & & & & & & & & & & \\
\hline & & & & & & & & & & & & & & & & & & & & & & 8.1 & 8. & & & & & & & & & 7 & 7.2 & 11. & 9.1 & & & \\
\hline & 12.5 & & & & & & & & & & & & & & & & 0.5 & & & & & 19 & & $-19.0 \mid-1$ & $-\left.76.5\right|^{-3}$ & -0.00 & & & & & $1.1\}^{-1}$ & & & & & & 37.0 & \\
\hline & & & & & & & & & & & & & & & & & & & & & & \begin{tabular}{l|l}
12.9 & 1 \\
\end{tabular} & & 129 & 113,2 & .5 & & & 3.7 & & & \begin{tabular}{|l|l}
8.0 & 1 \\
\end{tabular} & & & 14.4 & 13. & 23.4 & \\
\hline & & & & & & & & & & & & & & & & & & & & & & 4.0 & & & & & & & \begin{tabular}{|c|c|}
-11.8 \\
\end{tabular} & & & & 20 & 0.0 & 3.5 & 3.5 & 17.3 & \\
\hline & 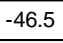 & & & & & & & & & & & & & & & & & & & & & & & -74.1 & -4.9 & & & & 51.8 & & & & & & & 63 & 33.8 & \\
\hline & & & & & & & & & & & & & & 4.1 & $\begin{array}{l}770 \\
\end{array}$ & & & 44 & & & & \begin{tabular}{ll|}
1.8 \\
\end{tabular} & 2.0 & \begin{tabular}{l|l}
2.1 & 1
\end{tabular} & \begin{tabular}{|l|l|}
1.3 & \\
\end{tabular} & \begin{tabular}{l|l}
-3.3 \\
\end{tabular} & -3.1 & 1.3 & \begin{tabular}{l|}
-2.8 \\
\end{tabular} & -3.0 & & \begin{tabular}{l|l}
-0.6 & 1 \\
\end{tabular} & 1.2 & 3.8 & 2.3 & 1.6 & 6.5 & \\
\hline & & & & & & 0.8 & & & & & & & & 0.8 & \begin{tabular}{|l|}
0.8 \\
\end{tabular} & 0.8 & ..8 & \begin{tabular}{l|l}
.8 \\
\end{tabular} & & 0.8 & 0.8 & \begin{tabular}{l|l}
0.8 \\
\end{tabular} & \begin{tabular}{|l|c|}
0.8 \\
\end{tabular} & 0.8 & \begin{tabular}{ll|l}
0.8 & 0 \\
\end{tabular} & \begin{tabular}{l|l}
0.8 & 0 \\
\end{tabular} & 0.8 & 0.8 & 0.8 & \begin{tabular}{|l|}
0.8 \\
\end{tabular} & \begin{tabular}{l|l}
0.8 \\
\end{tabular} & \begin{tabular}{l|l}
0.8 \\
\end{tabular} & \begin{tabular}{l|l}
0.8 & 0 \\
\end{tabular} & 0.8 & 0.8 & $0 . \varepsilon$ & 0.8 & \\
\hline & & & & & & & & & & & & & & & & & & & & & & & & & \begin{tabular}{|l|l}
1.1 & 1
\end{tabular} & & & & & & & & & & & & & \\
\hline & & & & & & & & & & & & & & 0.3 & & & & .3 & & & & 0.3 & 0.3 & 0. & 0.3 & 0.3 & 0.3 & & 0.3 & & & & & 0. & 0. & 0. & 0.3 & \\
\hline & & & & & & & & & & & & & & 0.8 & . & 0.6 & .8 & .8 & & & & 0.8 & 0.8 & 0.8 & 0.8 & 0.8 & 0.8 & & 0.8 & & c & 0.8 & 0.8 & 0.8 & 0.8 & & 0.0 & \\
\hline & & & & & & & & & & & & & & & & & & & & & & & & & & & & & & & & & & & & & & \\
\hline & & & & & & & & & & & & & & 1.7 & $t$ & 2.5 & 1.4 & 0.7 & 11.8 & & & \begin{tabular}{l|}
1.5 \\
\end{tabular} & 0.4 & 1.1 & 1.2 & 1.1 & 1.1 & & 1.0 & & 0 & 0.7 & 0.4 & 1.6 & & & 0.3 & \\
\hline & & & & & & & & & & & & & & & & & & & & & & & & & & & & & & & & & & & & & & \\
\hline & & & & & & & & & & & & & & \begin{tabular}{l|l}
0.4 \\
\end{tabular} & & 8 & 0.6 & 3.3 & & & & 3 & \begin{tabular}{l|l}
-1.4 & - \\
\end{tabular} & \begin{tabular}{c|c}
-0.3 & 0 \\
\end{tabular} & 0.8 & 1.0 & 1.0 & & 1.0 & & 1.2 & 0.5 & 0.8 & 2.1 & 1.7 & 1.5 & 3.5 & \\
\hline 8 & 6.6 & & & & & & & & & & & & & & & & 8.2 & 77.7 & & & & & $\begin{array}{l}9.9 \\
\end{array}$ & 14 & 1.8 & 0.5 & 0.4 & & -0.3 & & & & & & & & & \\
\hline & & & & & & & & & & & & & & & & & & & & & & & & & & & & & & & & & & & & & & \\
\hline 0 & 02 & & & -54 & -43.4 & & & & & & & & & & & & & 31.5 & & & & & & & -24 & 15. & & & & & & & & & & 8 & & \\
\hline 1 & & & & & & & & & & & & & & & & & & & & & & & & & & & & & & & & & & & & & & \\
\hline & & & & & & & & & & & & & & 2.0 & & & .6 & 6 & 8.3 & & & -2. & 0.2 & 1.2 & 1.3 & 1.1 & 1.1 & & 1.0 & & 1. & 0.6 & 0.1 & 1.9 & 15 & 1.3 & 4.7 & \\
\hline 3 & 12.9 & & & & & & & & & & & & & -9. & & & & & & & & -1. & & -9.1 & 0.3 & & & & & & & & 0.5 & 8.8 & 6.4 & 10 & & \\
\hline & & & & & & & & & & & & & & & & & & & & & & 1. & & & & & & & & & & & & & & & & \\
\hline 5 & & & & & 0.8 & & & & 18 & & & & & + & & & 8 & & & & & 0.8 & 0.8 & 0 & 0.8 & 0.8 & 0.8 & 0.8 & 0.8 & & & 0.8 & 0.8 & 0.8 & & & 0.8 & \\
\hline & & & & & & & & & & & & & & & & & & & & & & \begin{tabular}{l|l}
2 & 1
\end{tabular} & & & 6.4 & & & & & & 5 & & & & & & & \\
\hline & & & & & & & & & & & & & & & & & & & & & & -0. & -0. & & & & & & & & & & & & & & 1.0 & \\
\hline 8 & 0.9 & & & & & & & & & & & & & & & & & & & & & 0. & & 0.4 & 0.9 & 0.9 & 0.9 & & & & & & 10 & 0.9 & 0.9 & 0.9 & 0.9 & \\
\hline & & & & & & & & & & & & & & & & & & & & & & & & & & & & & & & & & & & & & & \\
\hline 10 & -0.7 & & & & & & & & -0. & & & 0.9 & & & & -0. & .3 & & & & & -0. & -0. & -0.2 & 0.0 & 0.8 & 0.7 & 0.0 & 0.9 & & 0.2 & 0.4 & 0.0 & -0.5 & -0.1 & 0.0 & 1.0 & 1.4 \\
\hline & 2.5 & & & & & & & & 6. & & & 73. & & \begin{tabular}{|l|}
9.0 \\
\end{tabular} & \begin{tabular}{|l|l}
14.6 \\
\end{tabular} & 7.6 & 5.7 & 9] & & & & \begin{tabular}{l|l}
2.4 \\
\end{tabular} & 3.8 & 4.5 & 3.2 & 2 & -1.4 & 4 & \begin{tabular}{|c|}
-1.8 \\
\end{tabular} & $\begin{array}{l}5- \\
\end{array}$ & & \begin{tabular}{l|}
-4.2 \\
\end{tabular} & 2 & 2.9 & & & 1.3 & 9.6 \\
\hline & & & & & & & & & & & & & & & & & & & & & & & & & & & & & & & & & & & & & & \\
\hline 3 & 29.1 & & & & -0.9 & & & 12.0 & 9.2 & \begin{tabular}{|c|}
6.4 \\
\end{tabular} & & & 20.2 & & 2 & 24.6 & 8.6 & 1 & 14. & 19 & 16.1 & \begin{tabular}{ll|l}
-1.1 &
\end{tabular} & 2. & \begin{tabular}{l|l}
4.7 \\
\end{tabular} & 0.4 & $15.5 \mid-1$ & $\begin{array}{c}16.5 \\
-16.5\end{array}$ & -1.9 & & & $-15.9-2$ & -26.1 & \begin{tabular}{c|c|c}
-6.3 & 1
\end{tabular} & $\begin{array}{c}12.9 \\
\end{array}$ & -0.7 & & 3.8 & \\
\hline & & & & & & & & & & & & & & & & & & & & & & & & & & & & & & & & & & & & & & \\
\hline & 11 & 9. & & & & 4. & 3 & 2 & & & 0 & & & \begin{tabular}{|l|}
8.4 \\
\end{tabular} & \begin{tabular}{|l|l|}
12.2 \\
\end{tabular} & & 2 & \begin{tabular}{l|l}
5.6 & 6 \\
\end{tabular} & & & & 3. & 4. & \begin{tabular}{|l|l}
5.3 & 4 \\
\end{tabular} & \begin{tabular}{l|l}
4.5 & 2 \\
\end{tabular} & 2.0 & 1.8 & & 6 & & & $\begin{array}{ll}0.1 \\
\end{array}$ & \begin{tabular}{l|l}
2.7 & 1 \\
.
\end{tabular} & 1.0 & & & 8.5 & \\
\hline & 6.5 & & & & & & & & & & & & & & & & 8.1 & 7.0 & & & & $-3 . \varepsilon$ & -5. & 6.6 & -5.1 & 1.0 & & & -0.3 & & 40. & 2.2 & & 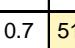 & & & & \\
\hline & 0.8 & & & & & & & & & & & & & & & & & & & & & & & & & & & & & & & & & & & & & \\
\hline & 0.4 & \begin{tabular}{|l|}
0.4 \\
\end{tabular} & \begin{tabular}{l|l|}
0.4 \\
\end{tabular} & \begin{tabular}{l|l|}
0.4 \\
\end{tabular} & \begin{tabular}{|l|}
0.4 \\
\end{tabular} & \begin{tabular}{l|l|l|}
0.4 \\
\end{tabular} & \begin{tabular}{|l|}
0.4 \\
\end{tabular} & 0.4 & 0.4 & 0.4 & 0.4 & 0.4 & \begin{tabular}{l|l}
0.4 \\
\end{tabular} & \begin{tabular}{|l|l|}
0.4 \\
\end{tabular} & \begin{tabular}{|l|l|}
0.4 \\
\end{tabular} & \begin{tabular}{l|l}
0.4 & $C$ \\
\end{tabular} & \begin{tabular}{l|l}
0.4 & 0 \\
\end{tabular} & \begin{tabular}{l|l}
0.4 & 0 \\
\end{tabular} & 0.4 & 0.4 & 0.4 & 0.4 & $\begin{array}{c}0.4 \\
\end{array}$ & \begin{tabular}{l|l}
0.4 & 0
\end{tabular} & \begin{tabular}{l|l|l}
0.4 & \\
\end{tabular} & \begin{tabular}{l|l}
0.4 & 0 \\
\end{tabular} & 0.4 & 0.4 & 0.4 & 0.4 & & 0.4 & \begin{tabular}{l|l}
0.4 & 0 \\
\end{tabular} & \begin{tabular}{l|l}
0.4 & 0
\end{tabular} & \begin{tabular}{l|l}
0.4 \\
\end{tabular} & 0.4 & & \\
\hline
\end{tabular}


Table D6. Leak flows obtained with 10 pressure sensors and 5 flowmeteres (nodes 2, 5, 8, 18, 19, 20, 27, 30, 32, 36 and pipes 11, 17, 25, 36, 42)

\begin{tabular}{|c|c|c|c|c|c|c|c|c|c|c|c|c|c|c|c|c|c|c|c|c|c|c|c|c|c|c|c|c|c|c|c|c|c|c|c|c|c|c|}
\hline & & & & & & & & & & & & & & & & & & & & & & & & & & & & & & & & & & & & & & \\
\hline & -6.3 & & & & & & & & & \begin{tabular}{|l|l}
3.6 \\
\end{tabular} & 3.6 & 4.1 & 52 & 5.8 & 10.0 & 87 & 48 & 51 & & & & & & 4.7 & 44 & 39 & & & & & & & & & & & & \\
\hline & & & & & & & & & & & 1.9 & 5.9 & 8.3 & & & & & & & & & & & & & & & & & & & & & & & & & \\
\hline & & & & & & & & & & & & & & & & & & & & & & & 5. & & & & & & & & & & & & & & & \\
\hline & & & & & & & & & & & & 24 & & & & & & & & & 8 & & & & -4.9 & -2. & & & & & & & & & & & & \\
\hline & & & & & & & & & & & 8 & 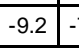 & & & & & & & & & & & -5.4 & -5.5 & -4.6 & & & & & & & & & & & & & \\
\hline & & & & & & & & & & \begin{tabular}{|l|l}
13.6 & 1
\end{tabular} & \begin{tabular}{|l|l}
15.6 & 1 \\
\end{tabular} & & & & & & & & & & & & & & & & & & & & & & & & & & & \\
\hline & & & & & & & & & & & & & & & & & & & & & & & & 4.9 & 26 & & & & & & & & & & 5.5 & & & \\
\hline & & & & & & & & & & & -40.3 & & & & -68.8 & & & & & 44.2 & -38.9 & & -13.0 & -14.1 & -4.9 & 60.3 & 56.5 & & 51.8 & & & & & & & & -8 & \\
\hline & & & & & & & & & & & 4 & & & & 7.0 & & & & & & & 1.8 & 2.0 & & 1.3 & & & & & & & & & & & & & \\
\hline & & & & & & & & & & & & & & & & & & & & & & & & & & & & & 0.8 & & & & & & & & 0 & \\
\hline & & & & & & & & & & & & & & & $\mid 1.4$ & & & & & & & & 2.5 & & & & & & 5.3 & & & & & & & & & \\
\hline & & & & & & & & & & & & & & & \begin{tabular}{l|l}
3.3 \\
\end{tabular} & & & & & & & & & & & & & & & & & & & & & & & \\
\hline & & & & & & & & & & & .8 & & & & 0.8 & & & & & & & .8 & 0.8 & 0.8 & & & & & $0 . \varepsilon$ & & & & & & & & 0 & \\
\hline & & & & & & & & & & & & & & & & & & & & & & & & & & & & & & & & & & & & & & \\
\hline & & & & & & & & & & & & & & & & & & & & & & & & & & & & & & & & & & & & & & \\
\hline & & & & & & & & & & & & & & & 8.0 & & 9.3 & $\begin{array}{l}5.1 \\
5\end{array}$ & 11.7 & 64 & 56.1 & 3.6 & $\begin{array}{l}11.3 \\
\end{array}$ & 15.2 & 11.8 & & & & 7.1 & & & & $4 \varepsilon_{1}$ & 31 & 31.4 & -1 & & \\
\hline & & & & & & & & & & & & & & & & & & & & & & & & & & & & & & & & & & & & & 5 & 5.0 \\
\hline & & & & & & & & & & & & & & & & & & & & & & & & & & & & & & & & & & & & & & \\
\hline & & & & & & & & & & & -2.6 & \begin{tabular}{l|l}
3.8 & . \\
\end{tabular} & & & 29 & \begin{tabular}{l|l}
3 &
\end{tabular} & & .0 & 29.1 & & & & & 0.9 & & & & & & & & & & & & & & \\
\hline & & & & & & & & & & & & & & & & & & & & & & & & & & & & & & & & & & & & & & \\
\hline & & & & & & & & & & & & $1 . 6 \longdiv { 3 }$ & & & \begin{tabular}{|l|}
46.4 \\
\end{tabular} & & & & & & & & & 18.8 & .6 & 10.1 & & & & & & & & & & & 67 & \\
\hline & & & & & & & & & & & & & & & & & & & & & & & & 1.2 & & & & & 1.0 & & & & & 1 & 1 & 1.3 & 7 & \\
\hline & & & & & & & & & & & & & & & & & & & & & & & & & & & & & & & & & & & & & & \\
\hline & & & & & & & & & & & & & & & & & & & & & & & & & & & & & & & & & & & & & & \\
\hline & & & & & & & & & & & & & & & & & & & & & & & & & & & & & & & & & & & & & & \\
\hline & & & & & & & & & & & & & & & & & & & & & & & & & & & & & -58.6 & -1 & 1 & & & & & & & \\
\hline & & & & & & & & & & & & & & & & & & & & & & & & & & & & & & & & & & & & & & \\
\hline & & & & & & & & & & & & & & & & & & & & & & & & & & & & & & & & & & & 0.8 & & & \\
\hline & & & & & & & & & & & & & & & 36.3 & & & & & & & & 7.0 & & & & & & 9 & & & & 2 & 9 & 9. & & & \\
\hline & & & & & & & & & & & & & & & & & & & & & & & & & & & & & & & & & & & & & & \\
\hline 3 & & & & & & & & & & & ו & & & & \begin{tabular}{l|l|l}
14.6 \\
\end{tabular} & & & & & & & & & & & & -1.4 & & -1.8 & & & & & 2.9 & & & & \\
\hline & & & & & & & & & & & & & & & & & & & & & & & & & & & & & & & & & & & & & & \\
\hline & & & & & & & & & & & & & & & & & & & & & & & & & & & & & & & & & & & & & & \\
\hline & & & & & & & & 0 & 9 & & & $.9 \mid$ & 0.9 & 0.9 & 0.9 & & 0.9 & $0.9 \mid 0$ & 0.9 & & & 0.9 & & 0.9 & 0.9 & & & & 0.9 & 0. & 0. & 0 & 0.9 & 0.9 & 0.9 & & & \\
\hline & & & & & & & & & & & & & & & & & & & & & & & & & & & & & & & & & & & & & & \\
\hline & & & & & & & & & & & & & & & & & & & & & & & & & & & & & & & & & & & & & & \\
\hline & . & & & & & & & & 0 & & & & & 0.8 & 0.8 & $0 . \varepsilon$ & & & & & & & & 0.8 & & & & & & & 0 & 0 & 0 & 0.8 & 0.8 & & & \\
\hline & & & & & & & & & & & & & & & & & & & & & & & & & & & & & & & & & & & & & & \\
\hline
\end{tabular}


Table D7. Leak flows obtained with 15 pressure sensors (nodes 2, 5, 8, 10, 13, 18, 19, 20, 24, 27, 28, 30, 32, 34, 36)

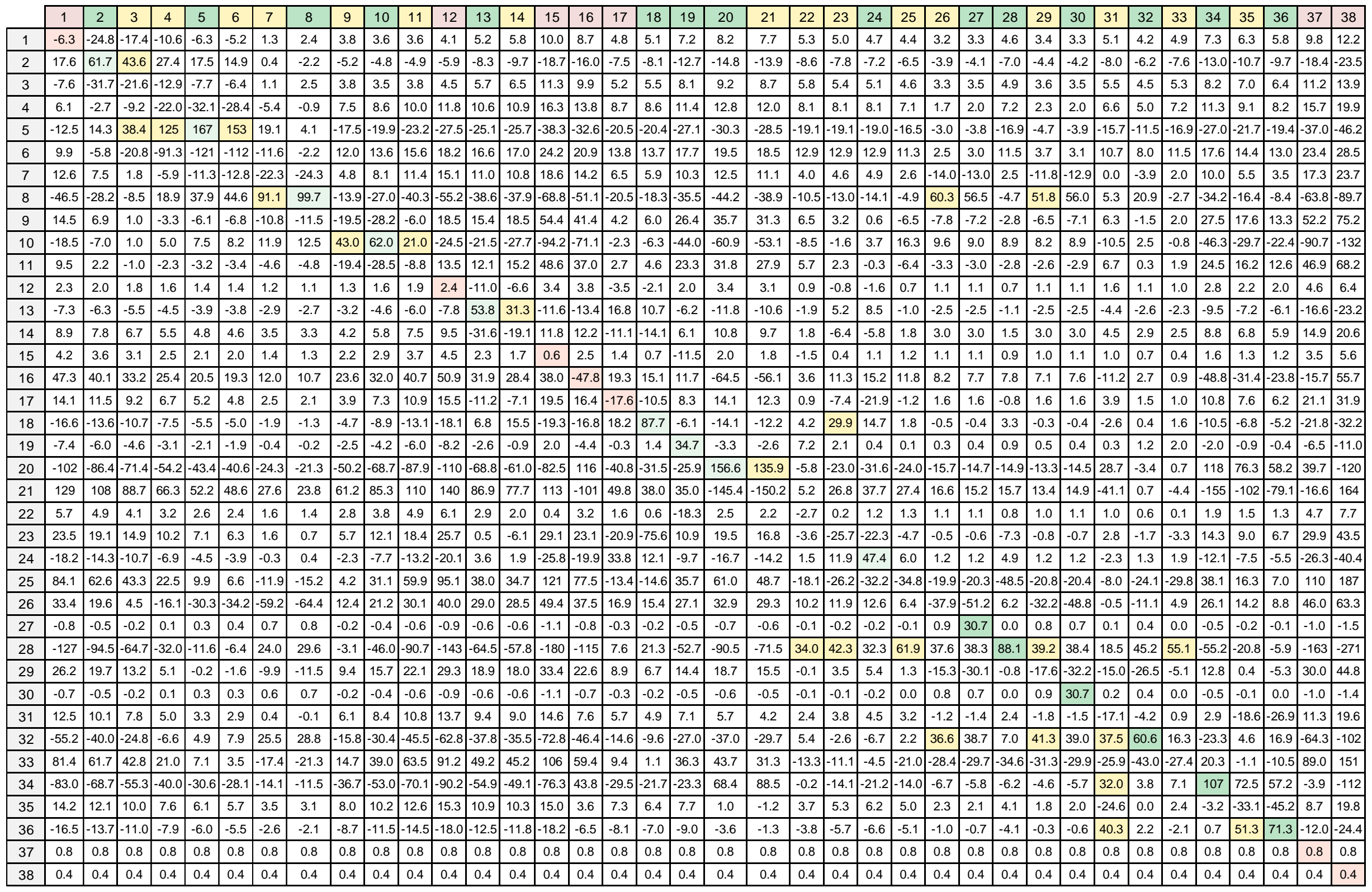


Table D8. Leak flows obtained with 15 pressure sensors and 5 flowmeteres (nodes 2, 5, 8, 10, 13, 18, 19, 20, 24, 27, 28, 30, 32, 34, 36 and pipes $11,17,25,36,42)$

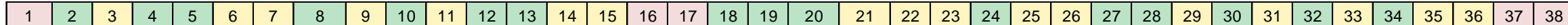

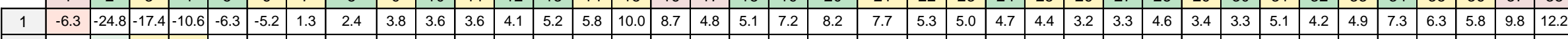

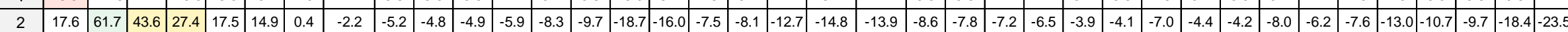

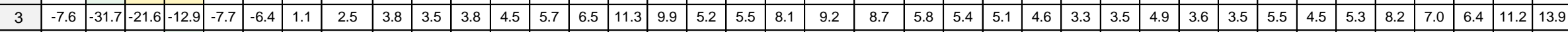

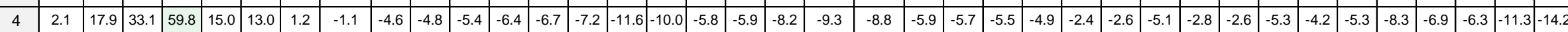

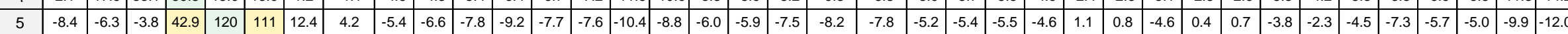

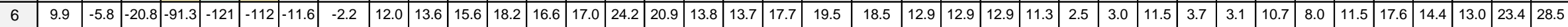

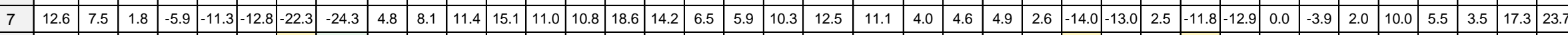

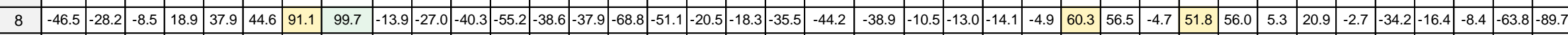

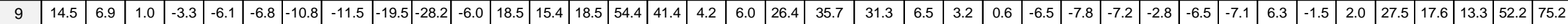

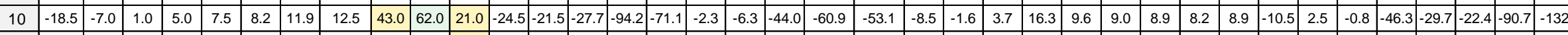

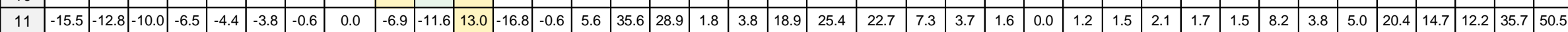

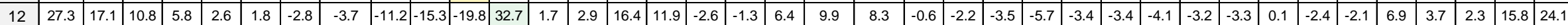

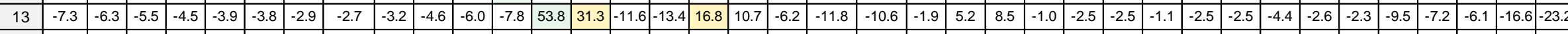

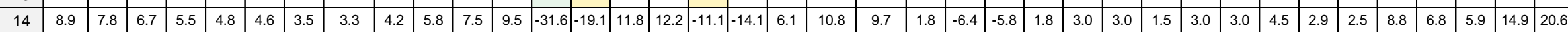

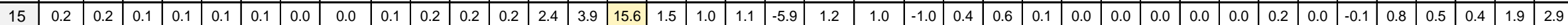

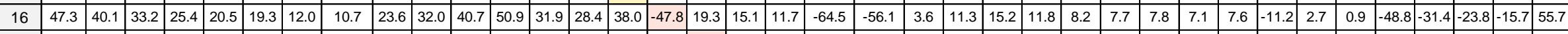

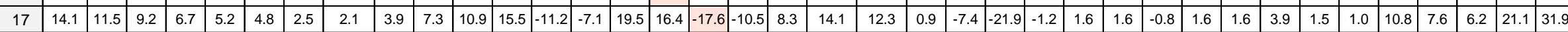

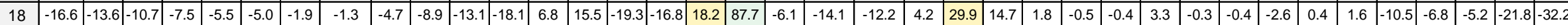

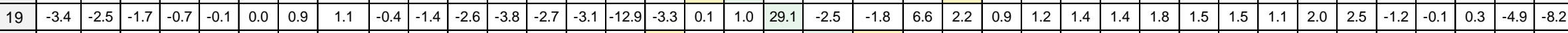

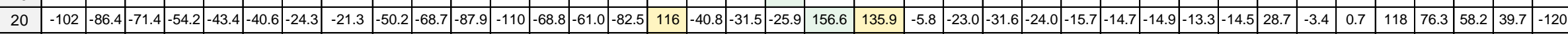

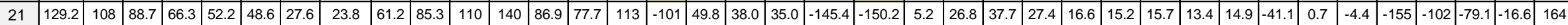

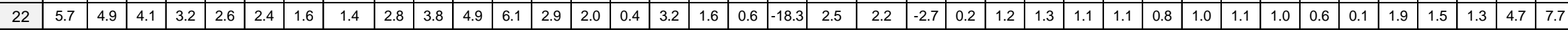

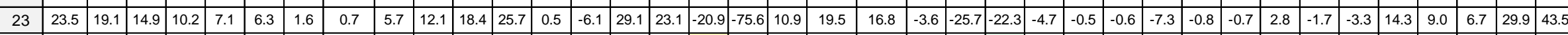

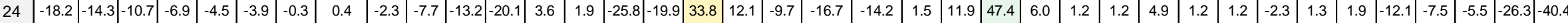

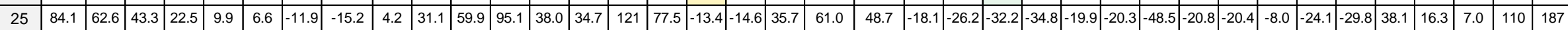

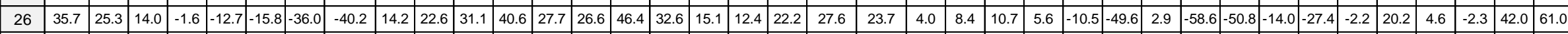
\begin{tabular}{llllll|l|l|l|l|l|l|l|l|l|l|l|l|l|l|l|l|l|l|l|l|l|l|l|l|l|l|l|l|l|l|l|l|l}
27 & -0.8 & -0.5 & -0.2 & 0.1 & 0.3 & 0.4 & 0.7 & 0.8 & -0.2 & -0.4 & -0.6 & -0.9 & -0.6 & -0.6 & -1.1 & -0.8 & -0.3 & -0.2 & -0.5 & -0.7 & -0.6 & -0.1 & -0.2 & -0.2 & -0.1 & 0.9 & 30.7 & 0.0 & 0.8 & 0.7 & 0.1 & 0.4 & 0.0 & -0.5 & -0.2 & -0.1 & -1.0 & -1.5 \\
\hline
\end{tabular}

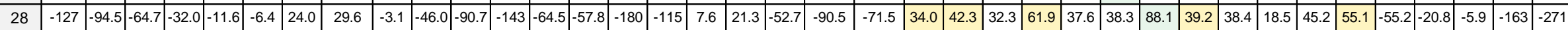

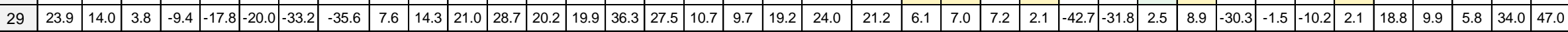

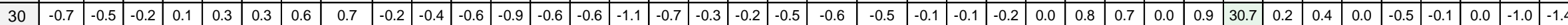

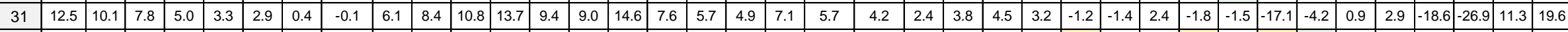

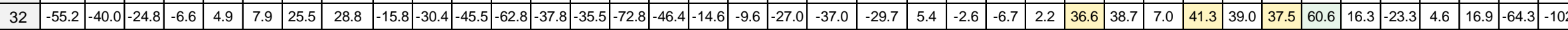

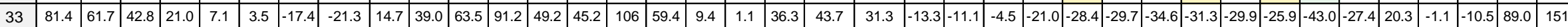

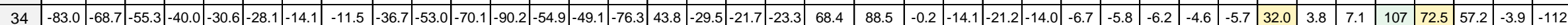

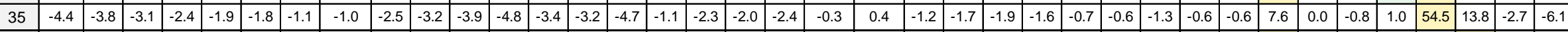

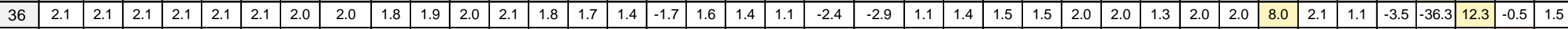

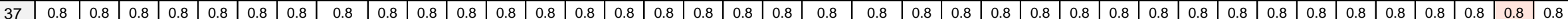

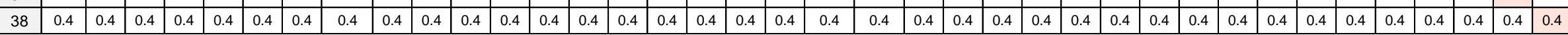

